\title{
SST subseasonal variability in the central Benguela upwelling system as inferred from satellite observations (1999-2009)
}

\author{
Katerina Goubanova, ${ }^{1}$ Séréna Illig, ${ }^{1}$ Eric Machu, ${ }^{2}$ Véronique Garçon, ${ }^{1}$ and Boris Dewitte ${ }^{1}$ \\ Received 23 December 2012; revised 21 June 2013; accepted 22 June 2013; published 5 September 2013.
}

[1] Subseasonal variability of Sea Surface Temperature (SST) in the central Benguela upwelling system is investigated using TMI satellite-derived data over the period 19992009. Spatial patterns and time-frequency characteristics of subseasonal variability are documented based on Empirical Orthogonal Functions (EOF) decomposition and wavelet analysis. Despite the land contamination of the TMI satellite data within approximately $100 \mathrm{~km}$ off the coast the first EOF of SST anomalies allows characterizing the coastal upwelling variability at the subseasonal scale. Two regimes of variability are evidenced: a submonthly (2-30 days) regime with a dominant 11 days oscillation and a lower frequency intraseasonal (30-90 days) regime with a dominant 61 days oscillation. Both regimes are modulated, to a large extent, by the local surface wind stress and are consistent with Ekman dynamics. The seasonality of the relationship between wind stress and SST for submonthly (intraseasonal) regime is characterized by a marked semiannual (annual) cycle, which is explained in terms of the impact of seasonal change of the upper ocean stratification on the vertical advection process. The wind-driven SST subseasonal variability is shown to be associated with eastward propagating disturbances in the midlatitudes corresponding to a wave number 4. The results also suggest an important role of the Antarctic Oscillation in modulating the intraseasonal wind-driven SST variability. The characteristics of the equatorial intraseasonal Kelvin waves are documented in order to discuss possible impact of remote oceanic forcing on SST variability along the coast in the Benguela upwelling system.

Citation: Goubanova, K., S. Illig, E. Machu, V. Garçon, and B. Dewitte (2013), SST subseasonal variability in the central Benguela upwelling system as inferred from satellite observations (1999-2009), J. Geophys. Res. Oceans, 118, 4092-4110, doi:10.1002/jgrc.20287.

\section{Introduction}

[2] The Benguela Current system is situated in a nearcoastal oceanic region in the South-East Atlantic, between the southern tip of Africa and the Angola-Benguela Frontal Zone (ABFZ) that is located at approximately $16^{\circ} \mathrm{S}$ (Figure 1) [Hutchings et al., 2009; Veitch et al., 2010]. It is one of the four eastern boundary upwelling systems and the major upwelling system of the Southern Hemisphere, along with the Humboldt Current system. The mean regional oceanic circulation is controlled to a large extent by the low-level alongshore equatorward winds associated with the eastern flank of the semipermanent South Atlantic Anticyclone (SAA). Through Ekman dynamics [Pedlosky, 1987], these winds force coastal upwelling of cold, deep,

\footnotetext{
${ }^{1}$ Laboratoire d'Etudes en Géophysique et Océanographie Spatiales, CNRS/IRD/UPS/CNES Toulouse, France.

${ }^{2}$ Laboratoire de Physique des Océans, UMR6523, CNRS/Ifremer/IRD UBO, Technopole de la pointe du Diable Plouzané, France.

Corresponding author: K. Goubanova, Laboratoire d'Etudes en Géophysique et Océanographie Spatiales, CNRS/IRD/UPS/CNES, 14 Ave., Edouard Belin, Toulouse FR-31400, France.

(katerina.goubanova@legos.obs-mip.fr)

(C)2013. American Geophysical Union. All Rights Reserved. 2169-9275/13/10.1002/jgrc.20287
}

nutrient rich water that provides favorable conditions for the development of a very productive oceanic ecosystem. On the basis of distinct physical and biological features, the Benguela system can be separated into three zones characterized by different upwelling regimes [e.g., Jury et al., 2013]: northern $\left(\sim 14-20^{\circ} \mathrm{S}\right)$, where upwelling is affected by the intrusion of tropical waters [Rouault, 2012]; central, with perennial upwelling (the main focus of this study); and southern (south of $32^{\circ} \mathrm{S}$ ), with summer upwelling and a southern boundary formed by warm-water regime from the Agulhas current [Hutchings et al., 2009].

[3] Many studies aiming at understanding the regional climate variability in the Benguela system focused on the interannual time scale [e.g., Shannon et al., 1986; Florenchie et al., 2003, 2004; Rouault et al., 2007; Lübbecke et al., 2010; Richter et al., 2010]. They are motivated by the important economic and ecological impacts of the interannual warm events observed along the Angolan and Namibian coasts (from $5^{\circ} \mathrm{S}$ to $27^{\circ} \mathrm{S}$ ) and called the Benguela Niño. The exact triggering mechanism of the Benguela Niño remains unclear, although it has been shown to be connected to some aspects of the equatorial Atlantic variability [Doi et al., 2007; Rouault et al., 2007; Lübbecke et al., 2010; Rouault, 2012] with a substantial contribution of meridional wind anomalies along the southwest African coast [Richter et al., 2010]. So far, little work has been 
(a)

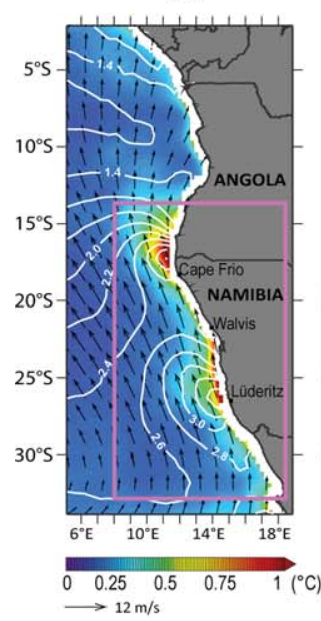

(b)

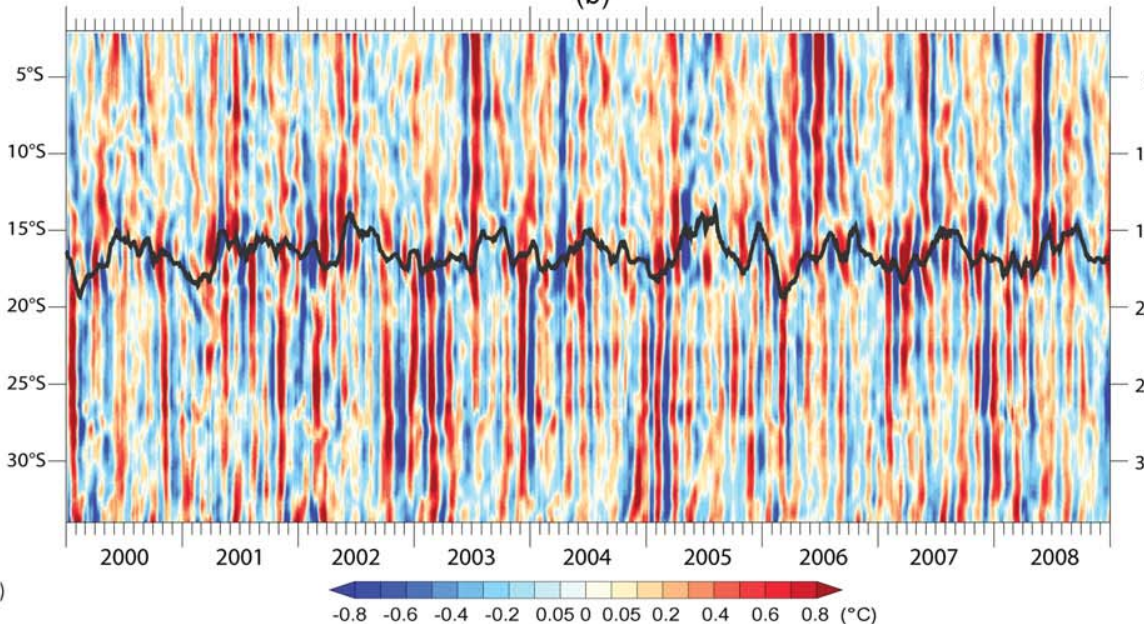

(c)

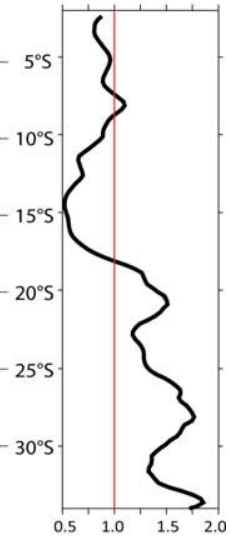

Figure 1. (a) Benguela upwelling region: subseasonal (see section 2 for the filtering procedure) SST variability (color shading, ${ }^{\circ} \mathrm{C}$ ), mean wind vector (arrows, $\mathrm{m} / \mathrm{s}$ ), and wind variability (contour, $\mathrm{m} / \mathrm{s}$ ) over the period 2000-2008. The pink rectangle indicates the region of interest of the present study. (b) Hovmuller diagram of the SST subseasonal anomalies $\left({ }^{\circ} \mathrm{C}\right)$ along the African coast, from the equator to $34^{\circ} \mathrm{S}$, averaged over the coastal fringe of $150 \mathrm{~km}$ based on the OI TMI land mask. (c) Ratio of the scaleaveraged wavelet power over the 2-30 day ${ }^{-1}$ frequency band to those over the $30-90$ day $^{-1}$ frequency band estimated for the SST anomalies shown in Figure 1b. It illustrates that south of ABFZ the SST experiences relatively higher-frequency variability than north of ABFZ. Black line in Figure 1b shows the position of the ABFZ defined as the latitude where the SST meridional gradient is the maximum. Note that Veitch et al. [2006] suggest that over the 100-250 km costal band the ABFZ is more diffuse relative to near-coastal regions ( $30 \mathrm{~km}$ offshore). The SST and wind data are derived from the TMI and QuikSCAT satellite observations, respectively.

done to document the SST variability in the Benguela system at the subseasonal time scale (2-120 days) although it is also likely associated with societal impact for surrounding countries.

[4] Along the southwestern African coast, the sea surface temperature (SST) experiences two distinct regimes of variability at the subseasonal time scale, north and south of the ABFZ. North of the ABFZ, between $16^{\circ} \mathrm{S}$ and the equator, the SST variability is rather weak (Figure 1a) and dominated by subseasonal oscillations at relatively low frequency (with periods larger than 30 days) (Figures $1 \mathrm{~b}$ and $1 \mathrm{c}$ ). This nearcoastal region is under the influence of the southward warm tropical Angola current that is strongly affected by the equatorial variability [Peterson and Stramma, 1991]. Significantly larger (Figure 1a) and, generally, higher-frequency (periods lower than 30 days) (Figures $1 \mathrm{~b}$ and 1c) subseasonal variability of SST is observed southward, in the Benguela upwelling system. It is modulated by the fluctuations of the cold northward Benguela upwelling current and is associated with relatively strong winds that exhibit large variability at the subseasonal time scale (Figure 1a). Thus, between $16^{\circ} \mathrm{S}$ and $34^{\circ} \mathrm{S}$ the mean wind speed (standard deviation of the wind subseasonal anomalies) averaged within the $250 \mathrm{~km}$ near-coastal band is $7.3 \mathrm{~m} / \mathrm{s}(2.8 \mathrm{~m} / \mathrm{s})$, while between the equator and $16^{\circ} \mathrm{S}$ it is less than $5 \mathrm{~m} / \mathrm{s}(1.5 \mathrm{~m} / \mathrm{s})$.

[5] In the Benguela upwelling system, there are two local maxima of SST subseasonal variability (Figure 1a): one located between $14^{\circ} \mathrm{S}$ and $17^{\circ} \mathrm{S}$ within approximately $2^{\circ}$ off the coast and the other one confined in a relatively narrow near-coastal fringe further south, between $\sim 22^{\circ} \mathrm{S}$ and $29^{\circ} \mathrm{S}$. Both maxima correspond to the respective maxima of wind variability. The first maximum of the SST subseasonal variability (standard deviation exceeds $1^{\circ} \mathrm{C}$ ) is observed just in the ABFZ whose position and intensity are modulated by opposing wind-driven northward and tropical southward currents [Mohrholz et al., 2001; Veitch et al., 2006; Colberg and Reason, 2006]. Thus, both flows contribute to the SST fluctuations over this zone, which explains the remarkably high-observed subseasonal SST variability. The intraseasonal variability in the ABFZ was documented by Hermes and Reason [2009] based on satellite SST and surface wind data over the period 1999-2004. Using a wavelet analysis, they identified a number of periods of strong power concentrated in two frequency bands, 20-30 day ${ }^{-1}$ and 30-64 day ${ }^{-1}$. These periods were found to be substantially modulated at interannual time scales.

[6] The second maximum of subseasonal SST variability in Figure 1a, located in a near-coastal band in the central Benguela region (standard deviation averaged within the $150 \mathrm{~km}$ off the coast between 22 and $29^{\circ} \mathrm{S}$ is $0.5^{\circ} \mathrm{C}$ ), is related directly to the variability of the Benguela upwelling current and is of main interest in this paper. To our knowledge, yet, no work has analyzed the subseasonal SST variability in this region. In this context, the present study, first, aims at documenting the spatial characteristics, seasonality and dominant frequencies of the SST variability at subseasonal scales in the central Benguela upwelling system. Second, we will attempt to identify the relative contribution of different forcing (local or remote) to this variability, with a particular focus on the atmospheric forcing. 
[7] The variability of the local wind forcing in the Benguela upwelling system was analyzed by Risien et al. [2004] based on satellite data over a 16 months period in 1999-2000. They showed that the wind variability spans the frequencies from 4 to 64 day $^{-1}$ with a number of relative peaks whose width and intensities differ along the coast with latitude. Thus, in the northern regions of the Benguela system (north of $23.5^{\circ} \mathrm{S}$ ), most of the wind energy occurs during austral winter within the 4-16 day ${ }^{-1}$ frequency band and is associated to a large extent with convective activity over West Africa and the Congo basin. The southern regions (south of $24^{\circ} \mathrm{S}$ ) are characterized by a bimodal power spectrum with dominant oscillations in the 412 and 25-50 day ${ }^{-1}$ frequency bands. Risien et al. [2004] suggest that the higher-frequency wind variability in this area is modulated by extratropical cyclones during austral winter and by mesoscale coastal lows during austral summer, whereas the lower-frequency wind variability appears to be linked to eastward propagating quasiperiodic wind events originated over eastern South America.

[8] Dewitte et al. [2011] focusing on the northern Humboldt Current system also evidenced two dominant regimes of frequency in the wind power spectrum corresponding to high-frequency (2-30 $\mathrm{day}^{-1}$ ) and low-frequency (30-90 day $^{-1}$ ) subseasonal oscillations. Both subseasonal regimes are associated with the dominant mode of covariability between wind and SST. The lead/lag relationship indicates that the SST variability is modulated, to a large extent, by wind fluctuations that are related to propagations of the migratory atmospheric disturbances across the South Pacific Anticyclone (SPA). Dewitte et al. [2011] further show that the two frequency bands correspond to different forcing mechanisms of SST, in particular with respect to their modulation by the seasonal cycle. Moreover for the lowfrequency intraseasonal regime, along with the local wind forcing, they suggest an important role of the oceanic Intraseasonal Equatorial Kelvin Waves (IEKW) that modulate the near-coastal thermocline depth while propagating along the coast, and represent an additional remote forcing for the SST. They also suggest that the local wind forcing at the frequency of the IEKW may be as well significant. Interestingly, in the southern part of the Humboldt upwelling system, at $30^{\circ} \mathrm{S}$, the role of the equatorial remote forcing appears to be important during strong Madden-Julian Oscillation (MJO) [Madden and Julian, 1994] activity [Rutllant et al., 2004]. The MJO-associated westerly wind bursts in the western Tropical Pacific force eastward propagating IEKW that, after reaching the South American coast, propagate poleward and modulate the wind-driven upwelling. Besides the oceanic teleconnections, a significant impact of the MJO on the regional subseasonal variability in the southern Humboldt system has been suggested through atmospheric teleconnections that induced changes in strengths of the SPA and, therefore, in alongshore upwelling-favorable wind [Rutllant et al., 2004; Rahn et al., 2012].

[9] In this paper, using satellite and reanalysis data over the period 1999-2009, we will document the SST subseasonal variability in the central Benguela upwelling system and associated forcing mechanisms, with a particular focus on its seasonal modulation. We wish to establish a "phenology" of the SST subseasonal variability considering the interplay of several processes affecting the regional SST (in particular, local wind and stratification) and their seasonal dependence. Our approach is guided by the one of Dewitte et al. [2011] for the northern Humboldt system taking into account the peculiarities of the Benguela system configuration. In particular, the impact of the remote oceanic forcing in the Benguela system is much less evident. While in the Humboldt upwelling system, the poleward propagation of the Tropical Pacific IEKW along the coast can be observed as far south as at $33^{\circ} \mathrm{S}$ [Hormazábal et al., 2001], along the southwestern African coast, the remote influence of the IEKW from the equatorial Atlantic seems to vanish just before the $\mathrm{ABFZ}$, at about $12^{\circ} \mathrm{S}$ [Polo et al., 2008].

[10] The paper is structured as follows. The next section introduces the observed data set and methods. Section 3 presents a detailed description of the spatial and temporal characteristics of the subseasonal SST variability. After examining the relationship between the SST and local wind stress in section 4, we analyze the large-scale atmospheric circulation patterns associated with their regional subseasonal fluctuations (section 5). A discussion on a possible role of other forcing mechanisms than the wind stress, in particular, those associated with IEKW, is presented in section 6 . Finally, the main conclusions are summarized in section 7.

\section{Data and Method}

\subsection{Data}

[11] The daily optimally interpolated (OI) SST product, derived from the Tropical Rainfall Measuring Mission (TRMM) [Kummerow et al., 2000] Microwave Imager (TMI), at quarter degree $(\sim 25 \mathrm{~km})$ resolution is employed in this study. The product is provided by the Remote Sensing Systems and is available from the 1 January 1998 at http://www.ssmi.com/sst/microwave_oi_sst_data_ description.html. The important feature of the microwave retrievals is that they are insensitive to atmospheric water vapor and thus can measure SST through clouds. This is a relevant issue over oceanic eastern boundary regions characterized by extended low-cloud coverage, such as the Benguela upwelling system. However, the major limitation to the microwave TMI observations is land contamination which results in biases of the order of $0.6 \mathrm{~K}$ within an approximately $100 \mathrm{~km}$ from the coast [Gentemann et al., 2010]. Since the large-scale OI bias correction does not allow eliminating the relative small scales of these biases [Reynolds et al., 2010], an extended land mask was used to remove the coastal TMI values before applying the OI procedure. Thus in the OI TMI product the offshore zone with no data extends at approximately $100 \mathrm{~km}$ from the coast. Although this limits to some degree the analysis of nearcoastal regions, in particular those dominated by coastal upwelling dynamics, we will show in section 3 that the OI TMI data still allow identifying the signature of upwelling variability at the subseasonal time scale further offshore.

[12] A particular feature of the TRMM satellite is its sun-asynchronous orbit that crosses the equator at the same local time every 47.5 days (46.4 days before August 2001 when the satellite was moved to a higher orbit of $402.5 \mathrm{~km}$ instead of $350 \mathrm{~km}$ ) [Negri et al., 2002]. As a result, subseasonal variability of TRMM-derived data is aliased by the 
diurnal cycle and exhibits a dominant oscillation with the 47 days cycle. This effect is particularly strong along the coastlines where SST diurnal warming amplitude is influenced by diurnal cycle over land. That is why, before applying the OI procedure, the TMI SST data were "normalized" to a daily minimum SST, based on a simple empirical model of diurnal warming [Gentemann, 2003]. Nevertheless, the 47 days cycle remains quite prominent in the data (not shown) and, therefore, this has to be kept in mind when interpreting the subseasonal TMI SST variability.

[13] The wind stress data set considered in this study consists of the gridded SeaWinds scatterometer zonal and meridional wind stress observations from the NASA satellite QuikSCAT. Homogeneous temporal series of daily mean wind stress fields, on global $0.5^{\circ} \times 0.5^{\circ}$ resolution grids, are generated from L2B product (distributed by JPL/ PO.DAAC) by French ERS Processing and Archiving Facility CERSAT (http://www.ifremer.fr/cersat/en/data/overview/gridded/mwfqscat.htm). Data are available over the period extending from the 20 July 1999 to 21 November 2009. There are a number of studies that provide comparisons of the SeaWinds with buoy and ship measurements of surface winds [e.g., Ebuchi et al., 2002; Bourassa et al., 2003; Chelton and Freilich, 2005]. For wind speed and direction the root-mean-square errors are both found to depend on wind speed, with average values of, respectively, $\sim 1 \mathrm{~m} / \mathrm{s}$ and $\sim 20^{\circ}$. In near-coastal region, due to land contamination QuikSCAT wind data are masked and no available within $25 \mathrm{~km}$ off the coast.

[14] Large-scale atmospheric forcing is examined based on the NCEP-NCAR reanalysis with $2.5^{\circ} \times 2.5^{\circ}$ spatial resolution [Kalnay et al., 1996]. Daily sea level pressure (SLP) and geopotential height at $500 \mathrm{hPa}$ (Z500) are used to characterize atmospheric large-scale circulation over the Southern Hemisphere.

[15] Intraseasonal Equatorial Kelvin Waves (IEKW) are estimated from the simple ocean data assimilation (SODA) reanalysis [Carton and Giese, 2008], version 2.1.6, that provides 5 days averaged oceanic fields with a spatial resolution of $0.5^{\circ} \times 0.5^{\circ}$ and 40 vertical levels. The IEKW are expressed in terms of the amplitude of the Kelvin wave contribution to the sea level anomalies. The contributions of the two first (the most energetic) vertical baroclinic modes are derived following the method described by Illig et al. [2004]. In previous studies, the method was successfully applied to the SODA data over the equatorial Pacific [Dewitte et al., 2003, 2008] and to an Oceanic Global Circulation Model data over the equatorial Atlantic [Illig et al., 2004].

\subsection{Filtering Procedure}

[16] In order to extract the subseasonal variability, a filtering procedure inspired from the one proposed by Lin et al. [2000] is used for all variables. First, monthly averages are calculated from daily data. The monthly time series are smoothed using a 1-2-1 filter and then interpolated on a daily temporal resolution using cubic spline. This lowfrequency component is subtracted from the original time series. In order to ensure that no seasonal cycle remains, the seasonal cycle of the resulting time series over the period 2000-2008 (interpolated on a daily basis using cubic spline) is also removed. The spectral characteristics of the high-pass filter designed in this way were examined using a Gaussian white noise. The resulting transfer function indicates that the filter reduces the input power by half at 168 day $^{-1}$, whereas the attenuations by $79 \%$ and $10 \%$ correspond to the frequencies of 117 day $^{-1}$ and 416 day $^{-1}$, respectively.

[17] Note that our filtering procedure results in a loss of 1.5 months of data at the beginning and at the end of the time series. Thus, given the period of overlap between TMI and QuikSCAT data, our analysis of the subseasonal anomalies of SST and wind stress covers a 10 years period from the 1 September 1999 to 31 August 2009.

\subsection{EOF Analysis}

[18] The upwelling circulation in the Benguela system is not spatially uniform along the coast. Local topography and meteorology together with changes in the coastal line orientation are responsible for the formation of a number of centers of intensified upwelling associated with locally enhanced wind stress curl [Lutjeharms and Meeuwis, 1987; Shannon and Nelson, 1996; Veitch et al., 2010]. In particular, in the central Benguela system there are three main upwelling centers: Lüderitz $\left(\sim 27^{\circ} \mathrm{S}\right)$, Walvis Bay $\left(\sim 24^{\circ} \mathrm{S}\right)$, and Namibia $\left(\sim 21^{\circ} \mathrm{S}\right)$ cells. Risien et al. [2004] suggest that the different upwelling centers are also characterized by different regimes of synoptic and/or intraseasonal wind variability.

[19] However, in this study, we do not focus on a detailed analysis of each of the main upwelling cells but, rather, we are interested in general features of subseasonal variability of SST. For this purpose, we consider the region extending from $32^{\circ} \mathrm{S}$ to $14^{\circ} \mathrm{S}$ and from $9^{\circ} \mathrm{E}$ to $18^{\circ} \mathrm{E}$, and document the dominant mode of SST variability based on classical empirical orthogonal function (EOF) decomposition [vonStorch and Zwiers, 1999]. We chose to normalize the spatial patterns (hereafter referred to as EOFs) and the associated time series (namely, Principal Components or PCs) such as the standard deviation of the time series is equal to one.

\subsection{Wavelet Analysis}

[20] Wavelet analysis is a powerful tool for detecting time-frequency variations within time series data. A detailed description of the wavelet analysis can be found in Torrence and Compo [1998]. In this study, to investigate the periods of high variance of the subseasonal fluctuations of the dominant modes of variability of SST and wind stress, we use continuous wavelet transform based on the Morlet function $\left(\omega_{O}=6\right)$.

[21] In order to be able to compare the magnitude of the wavelet spectrum at different frequencies, we estimate a Normalized Wavelet Power Spectrum (NWPS). Following the notations of Torrence and Compo [1998], giving a time series of length $N$ with equal time spacing $\delta t$, and estimating the wavelet transform $W_{n}\left(s_{j}\right)$ with wavelets of scale $s_{j}$ of resolution $\delta j$ and a largest scale $J$, the energy conservation $\sigma^{2}$ of the time series verifies: $\sigma^{2}=\frac{\delta j \delta t}{C_{\delta} N} \sum_{n=1}^{N} \sum_{j=0}^{J}$ $\frac{\left|W_{n}\left(s_{j}\right)\right|^{2}}{s_{j}}$. In this context, we define $N W P S=\frac{\delta t}{C_{\delta} s_{j}}\left|W_{n}\left(s_{j}\right)\right|^{2}$, such as the time average of NWPS, namely global NWPS, is composed of local variance contributions to the total energy of the time series and remains independent of the 


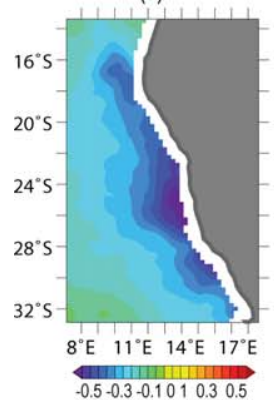

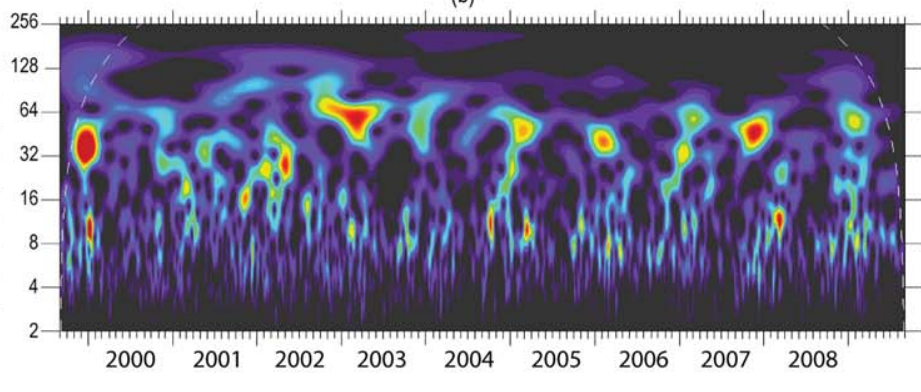

(c)

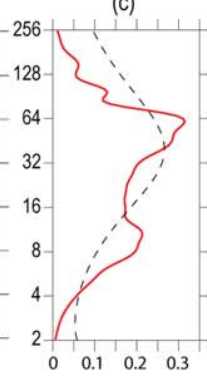

(d)

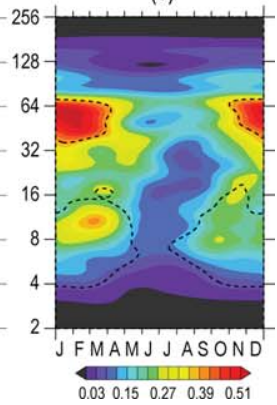

Figure 2. First mode of the EOF analysis of the subseasonal SST anomalies. (a) Spatial pattern $\left({ }^{\circ} \mathrm{C}\right)$, (b) Normalized Wavelet Power Spectrum (NWPS), (c) global NWPS, and (d) climatology of the NWPS for the associated time series. Dashed white line in Figure $2 b$ depicts the cone of influence indicating the bound below which the edge effects for wavelet spectrum become important. Black dashed lines in Figures $2 \mathrm{c}$ and $2 \mathrm{~d}$ show the $90 \%$ confidence level (see section 2 for the definition of the level of significance). Figures $2 \mathrm{~b}-2 \mathrm{~d}$ are in nondimensional units.

scale resolution $\delta j$. Note that $\delta j$ is chosen equal to $1 / 15$ and that the wavelet scale is chosen to be regular fractional power of $2: s_{j}=\delta t \cdot 2^{j \delta j}, j=0,1, \ldots, J$. Given that for the Morlet wavelet, the Fourier period is almost equal to the wavelet scale $\lambda_{j}=1.033 s_{j}$, the global NWPS peak areas can be compared between them in a base two period representation.

[22] Following Torrence and Compo [1998], significance levels are determined from $\chi^{2}$ distribution (with a number of degree of freedom $\nu$ ) using a background spectrum defined as a first-order autoregressive process having the same autocorrelation at lag -1 as our data. For the NWPS, $\nu$ is equal to 2 . For a time-averaged NWPS, $\nu$ depends on the number of points to average $n_{a}$ and can be estimated using equation (23) from Torrence and Compo [1998]. In the case of the global NWPS, $n_{a}$ corresponds to the total number of days within the considered 10 year period, whereas for the monthly climatological spectrum, we take $n_{a}$ equal to 300 (10 years $\times 30$ days per month).

\section{Spatial and Temporal Characteristics of the Subseasonal SST Variability}

[23] Figure 2 shows the dominant mode of variability of the subseasonal SST anomalies in the Benguela upwelling system. On average over the considered region, this mode explains $32 \%$ of the total variance. The first EOF (Figure 2a) is characterized by anomalies of the same sign over the entire region with amplitudes decreasing from the coast to offshore. The maximum amplitudes of anomalies with absolute values greater than $0.4^{\circ} \mathrm{C}$ are situated in the central Benguela region, just offshore of the most vigorous upwelling area, namely the Lüderitz upwelling cell, located at $26^{\circ}-27^{\circ} \mathrm{S}$. Two smaller local maxima along the coast are observed in northern and southern Benguela, at $17^{\circ} \mathrm{S}$ (Cape Frio upwelling cell) and $30^{\circ} \mathrm{S}$ (Namaqua cell), respectively. Note that the explained variance of the SST anomalies averaged in the $150 \mathrm{~km}$ coastal band between $16^{\circ} \mathrm{S}$ and $34^{\circ} \mathrm{S}$ is about $80 \%$.

[24] Although the accurate detection of the coastal upwelling should be based on the vertical velocity in the upper ocean layer very close to the coast [Estrade et al.,
2008], the SST can provide a proxy for the upwelling intensity. We will show in this section that the first EOF represents an offshore signature of the coastal upwelling variability. Thus, it can be used to document subseasonal upwelling variability, despite the resolution and the land mask of the OI TMI SST products that do not allow documenting the near-coastal SST variability at the spatial scales corresponding to the cross-shore upwelling length, estimated to be less than $10 \mathrm{~km}$ [Marchesiello and Estrade, 2010].

[25] Higher-order EOFs that explain smaller fraction of the total variance are not considered in this study. It is worth noting, that the second dominant mode (not shown), accounting for $11 \%$ of the total explained variance and representing a meridional dipole, explains about $35 \%$ of the local variance in the northern Benguela, over an alongshore area extending from $14^{\circ} \mathrm{S}$ to $19^{\circ} \mathrm{S}$ and over about $200 \mathrm{~km}$ offshore. In this area, the SST variability is associated with the fluctuations of the ABFZ (cf. Figure 1a).

\subsection{Time-Frequency Analysis}

[26] The NWPS of the SST PC1, i.e., of the time series associated with the dominant variability mode, evidences considerable variability in a large range of frequencies within the subseasonal time scale (Figure 2b). The Global NWPS of PC1 (Figure 2c) shows that significant power is concentrated mainly in the 30-90 days band, although there is also much power in the submonthly band peaking at about $7-15$ days. The most prominent significant peaks are centered around 61 and 11 days, respectively. Note the presence of the smaller significant peaks of power centered at 47 and 97 days. This analysis allows us to determine two dominant regimes of SST variability: (1) a high-frequency subseasonal variability, or submonthly regime, that corresponds to the 2-30 day ${ }^{-1}$ frequency band and represents $49 \%$ of the total power of the PC1 spectrum and (2) a lowfrequency subseasonal, or, strictly speaking, intraseasonal regime, that corresponds to the $30-90$ day $^{-1}$ frequency band and represents $41 \%$ of the total power of the PC1 spectrum. Comparable regimes of SST variability were evidenced in the Humboldt upwelling system along the Peruvian coast [Dewitte et al., 2011]. 
(a)

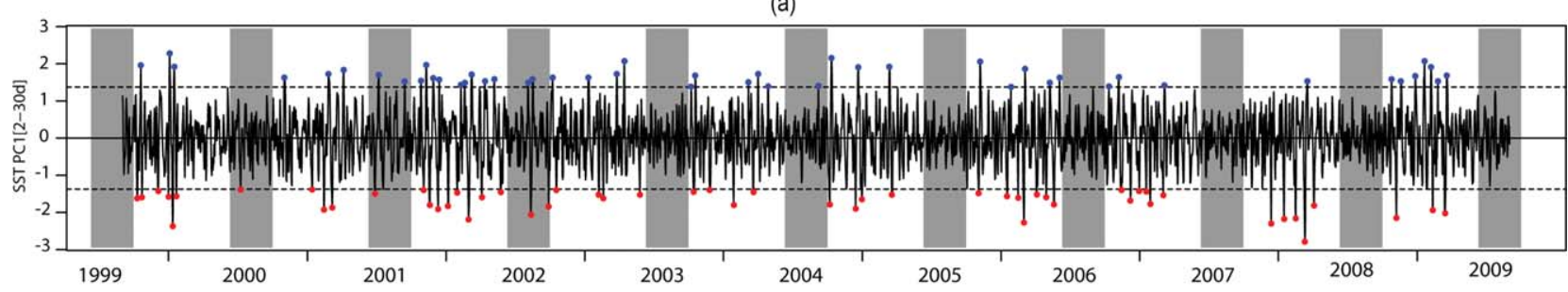

(b)

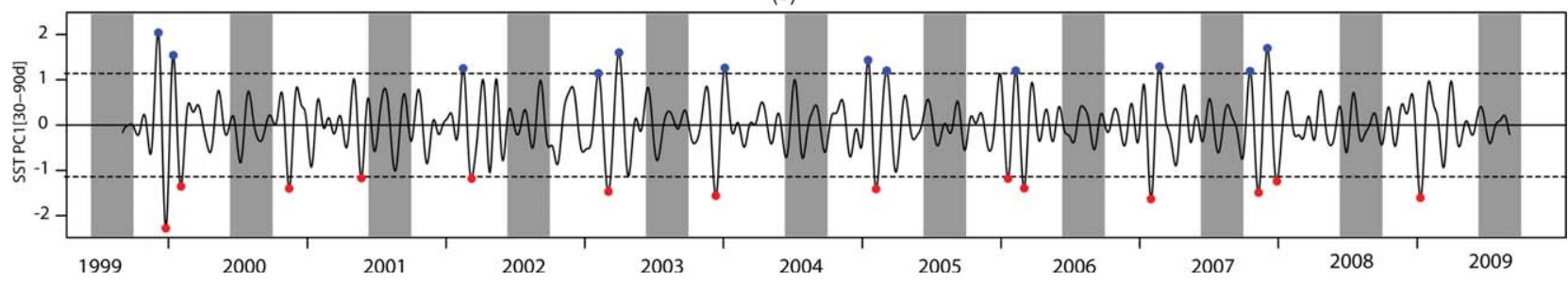

Figure 3. (a) 2-30 day $^{-1}$ and (b) 30-90 day ${ }^{-1}$ band-pass filtered (Lanczos) PC1 of the subseasonal SST anomalies corresponding to submonthly and intraseasonal regimes, respectively. Grey vertical rectangles show JJAS seasons. Dashed horizontal lines show \pm 2 standard deviations of the filtered series. Blue (red) points indicate the peaks corresponding to cold (warm) SST events (see text for the peak detection criteria).

[27] In order to identify whether there is a seasonal dependence of the intraseasonal SST variability or, in other terms, if the aforementioned regimes are favored at certain periods of the year, we calculate the climatology (monthly seasonal cycle) of the NWPS (Figure 2d). It reveals that for both regimes the period of strongest power in spectrum occurs during extended austral summer (from November to April). This can also be seen from the NWPS (Figure 2b): for each summer, from $2002 / 2003$ to $2008 / 2009$ there is a strong local maximum of wavelet power in the 45-90 day $^{-1}$ frequency band and numerous local maxima in the $7-15$ day $^{-1}$ frequency band. In section 4 , we will explore further the seasonal dependence of subseasonal SST variability. Interestingly, during the years 2001 and 2002 the dominant EOF mode exhibits a distinct variability with respect to the whole period. For instance, for these 2 years the maximum power is concentrated between approximately 15 and 45 days and the seasonal cycle of the variability is barely noticeable.

\subsection{Composite Evolution}

[28] In this subsection, we use a lagged composite analysis to examine the temporal evolution of the SST for the two dominant regimes of subseasonal variability evidenced above. First, in order to isolate the submonthly and intraseasonal regimes, the SST PC1 was filtered using, respectively, 2-30 days and 30-90 days Lanczos band-pass filters [Duchon, 1979] with 121 weights. The filtered series are shown in Figures $3 a$ and 3b, respectively. Here, it is important to keep in mind that the sign of the SST PC1 is defined with respect to the first EOF pattern shown in Figure 2a which portrays negative anomalies. This implies that positive (negative) values of the time series are associated with cold (warm) SST events. Then, for the composite analysis, the strongest cold (warm) subseasonal events (cf. blue (red) dots in Figure 3) were selected based on the following criteria: (a) the amplitude of the considered filtered time series is greater (less) than $2(-2)$ standard deviations and (b) it is the maximum (minimum) over the period bounded on both sides by the closest day with negative (positive) amplitude. The time for this event is denoted as "day 0."

[29] For the submonthly regime, the filtered SST PC1 shows 48 positive and 54 negative peaks and is slightly negatively skewed (the skewness coefficient is -0.1) (Figure 3a). Most of the peaks occur during the extended summer season, except for the years 2001 and 2002 when the peaks are observed all year round. This is consistent with the periods of highest SST variability for the 2-30 days band identified based on the wavelet analysis (Figure 2b). The filtered SST PC1 for the lower-frequency intraseasonal regime (Figure $3 \mathrm{~b}$ ) is also slightly skewed (the skewness coefficient is -0.1 ) and presents 12 positive and 14 negative peaks that form generally one or two cycles of strong cold-warm or warm-cold summer events. These cycles correspond to the periods of strong power in the 3090 days band of the wavelet power spectrum shown in Figure $2 b$.

[30] In order to map the SST composites for the submonthly and intraseasonal events, the subseasonal SST anomalies over the Benguela upwelling system are filtered with the same Lanczos filters that are applied to the SST PC1 to isolate the submonthly and intraseasonal regimes. Figure 4 displays the composite of the SST anomalies for the cold events corresponding to the submonthly regime. At lag -4 days there is a weak warm SST anomaly all over the region. Lag -3 days can be identified as the initiation phase of the cold submonthly event. Indeed, it is associated with a weak negative anomaly of about $0.1{ }^{\circ} \mathrm{C}$ near the coast in front of Cape Frio that, in the following day, intensifies rapidly along the coast to the central Benguela region until $26^{\circ} \mathrm{S}$, and extends offshore. The cold anomaly is well developed over the whole region, with the highest amplitudes near the coast, at lag -1 day. At the peak of the event (lag 0), the anomaly reaches $-0.35^{\circ} \mathrm{C}$ on average over the 
(a)

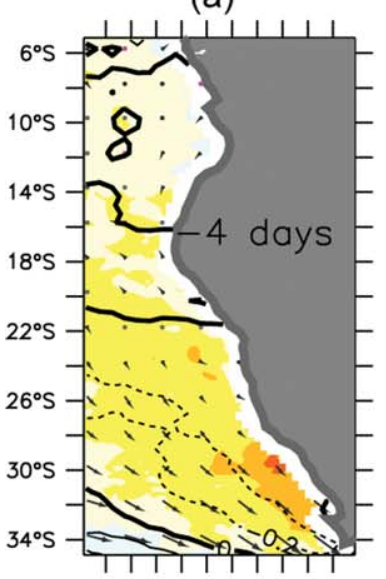

(e)

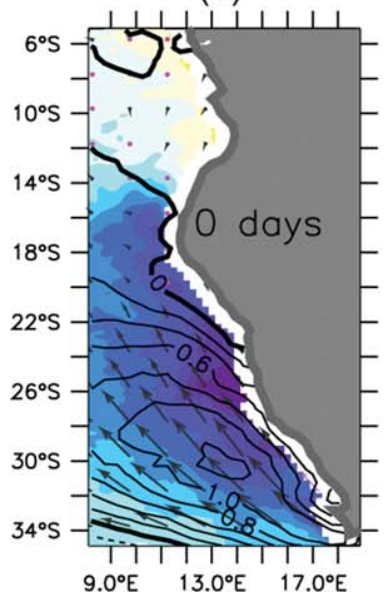

(b)

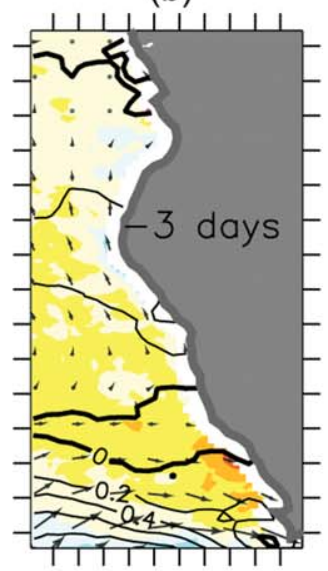

(f)

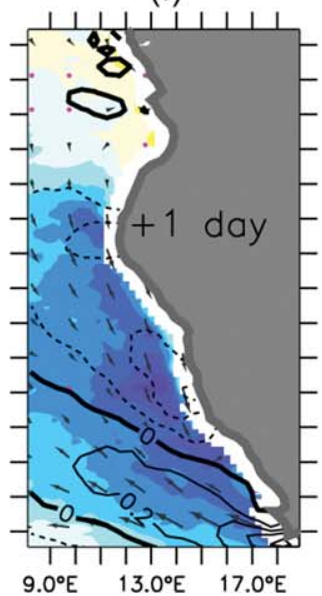

(c)

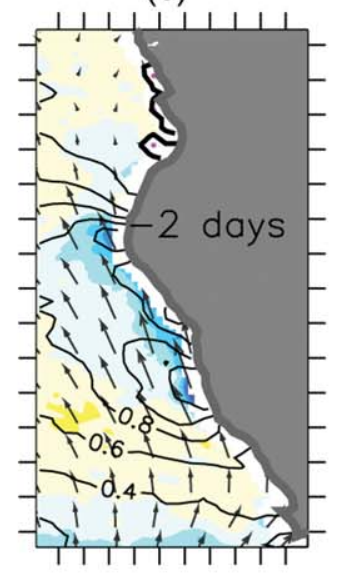

(g)

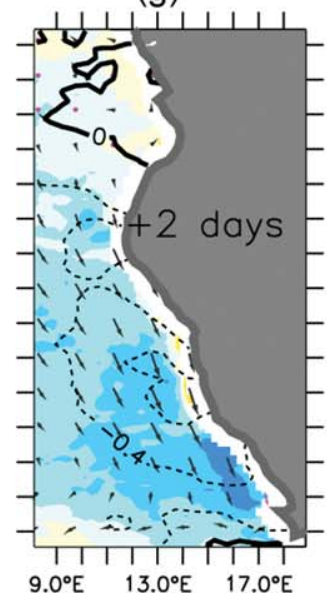

(d)

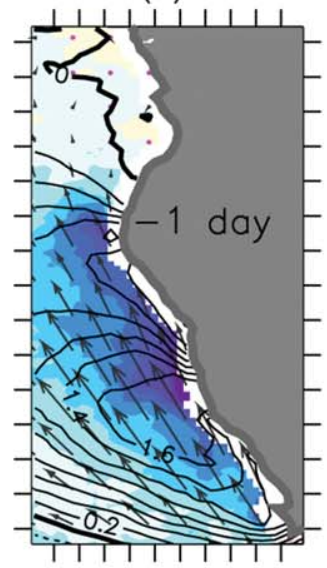

(h)

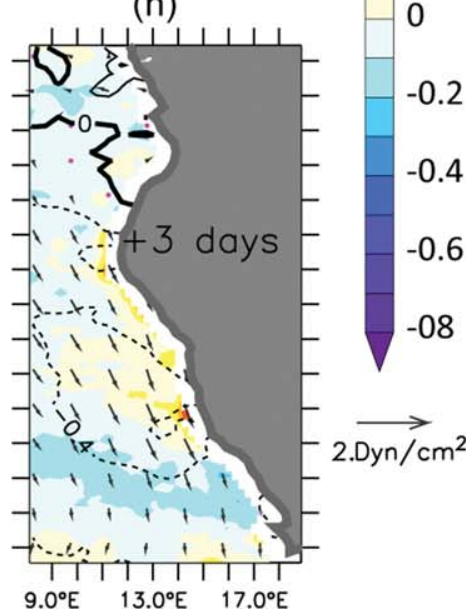

Figure 4. Time-lagged composites of submonthly anomalies of SST (color shading, in ${ }^{\circ} \mathrm{C}$ ), wind stress vector (arrows, in dyn $/ \mathrm{cm}^{2}$ ), and wind stress amplitude (contour, in dyn $/ \mathrm{cm}^{2}$ ) for the SST cold events identified based on the 2-30 day ${ }^{-1}$ band-pass filtered PC1 (Figure 3a). (a-h) The time lags are shown from -4 to +3 days.

region and $-0.75^{\circ} \mathrm{C}$ locally in the Lüderitz area $\left(24^{\circ}-28^{\circ} \mathrm{S}\right.$, $12^{\circ} \mathrm{E}$-coast) where its maximum is observed. During the following 2 days, the cold anomaly weakens and at lag +3 days the SST returns to near normal.

[31] The spatial evolution of warm anomalies and their amplitudes (not shown) is similar to those of cold anomalies but their development phase is longer whereas their decay phase is shorter. In particular, the initialization phase of the warm event corresponds rather to lag -4 days when a weak positive anomaly can be identified in the Cape Frio area and develops during the following day mostly along the coast. At lag -2 days, the warm anomalies already prevail over the entire region. After reaching the peak phase (at lag 0 the average anomaly amplitude is $0.38^{\circ} \mathrm{C}$ over the region, with the maximum of $0.82^{\circ} \mathrm{C}$ in the Lüderitz area), it lasts an additional day and completely disappears at lag +2 days.

[32] The cold anomaly composites for the intraseasonal regime are shown in Figure 5. As it is the case for cold submonthly events, negative SST anomaly appears first near the Cape Frio region. This initiation phase corresponds to lag -15 days. At lag -10 days, the cold anomaly is well developed all along the coast from $14^{\circ} \mathrm{S}$ to $30^{\circ} \mathrm{S}$, and at lag
-7 days it is extended further offshore. At the peak phase, the strongest values of anomaly $\left(<-0.5^{\circ} \mathrm{C}\right)$ are confined near the coast and show two local minima of approximately $-1{ }^{\circ} \mathrm{C}$ over the area ranging from Walvis Bay to Lüderitz $\left(22^{\circ} \mathrm{S}-26^{\circ} \mathrm{S}\right)$ and off Cape Frio. The anomaly averaged over the entire region is $-0.31^{\circ} \mathrm{C}$. During the next week, the cold anomaly weakens and at lag +7 days a positive anomaly starts to develop along the coast, corresponding certainly to the initiation phase of warm event of the intraseasonal cycle. The corresponding lag-composites for warm events (not shown) are very similar to those for cold events in terms of spatial and temporal evolution, as well as anomaly amplitude.

[33] The evolution of SST anomalies, from the coast to the offshore ocean, observed for both subseasonal and lower-frequency intraseasonal regimes, suggests that the first EOF of SST in Figure 2a represents an offshore signature of the coastal upwelling variability, with cold (warm) events corresponding to upwelling amplification (weakening) at submonthly and intraseasonal time scales, respectively. The submonthly variability is associated with larger offshore extension of SST anomalies compared with the low-frequency intraseasonal variability. Interestingly, for 
(a)

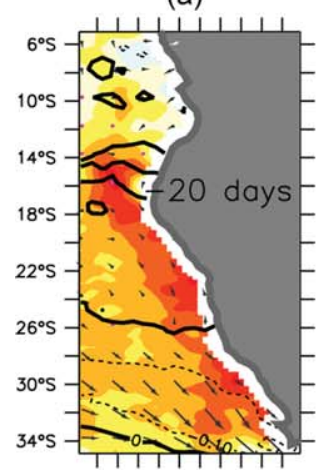

(f)

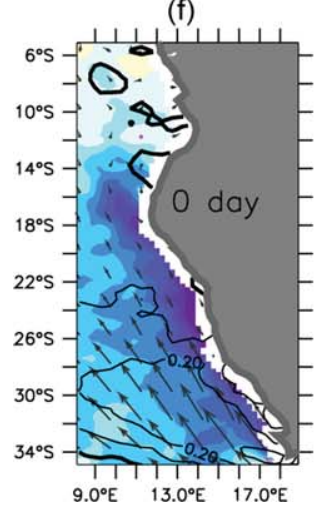

(b)

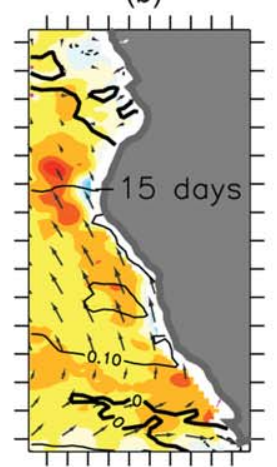

(g)

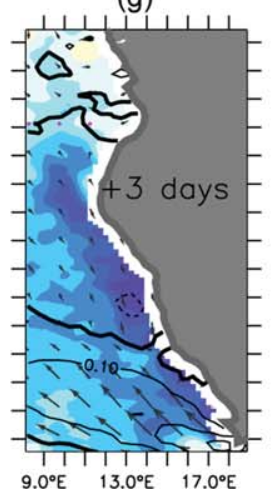

(c)

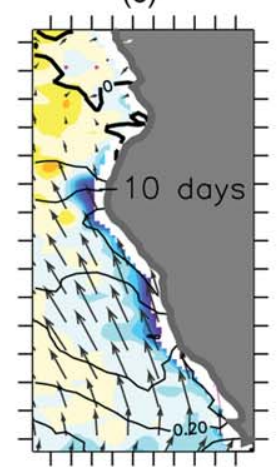

(h)

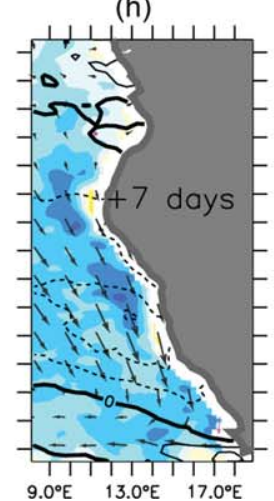

(d)

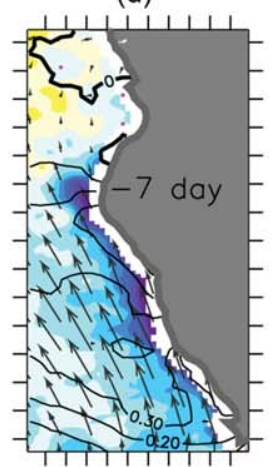

(i)

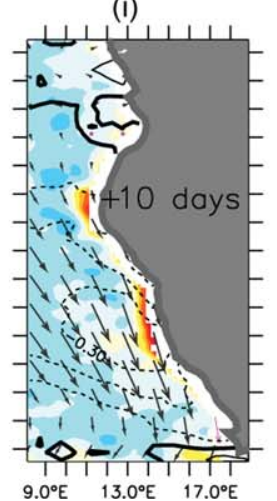

(e)

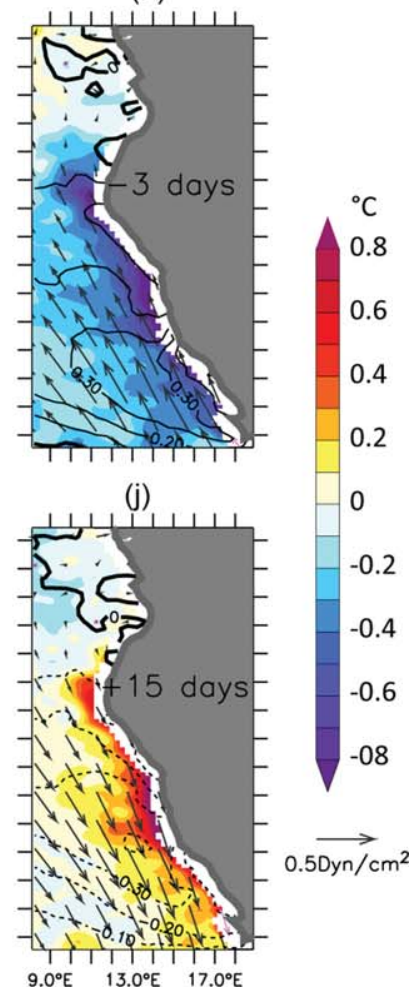

Figure 5. Time-lagged composites of the intraseasonal anomalies of SST (color shading, in ${ }^{\circ} \mathrm{C}$ ), wind stress vector (arrows, in dyn $/ \mathrm{cm}^{2}$ ), and wind stress amplitude (contour, in dyn/ $/ \mathrm{cm}^{2}$ ) for the SST cold events identified based on the 30-90 day ${ }^{-1}$ band-pass filtered PC1 (Figure 3b). On Figures 5a to $5 \mathrm{j}$ the time lags are shown at $-20,-15,-10-7,-3,0,+3,+7,+10$, and +15 days.

both regimes, during the initiation phases of the cold and warm events, the SST anomaly first manifests in the northern Benguela, front of Cape Frio, and then appears in the central part of the Benguela system along the coast and offshore. This would suggest a southward propagating signal along the coast, or would indicate that the regional dynamics in the Cape Frio region (associated with characteristics of upper ocean layer, coastal geometry and bathymetry or local forcing) favor a stronger upwelling and/or a faster offshore propagation of the coastal signal. The following analysis of the regional winds suggests that the latter is most likely the explanation.

\section{Regional Wind Forcing}

[34] In this section, we examine the variability of upwelling-favorable wind stress in order to interpret the SST variability from Ekman dynamics and the differences in spatial patterns between submonthly and intraseasonal time scales.

\subsection{Wind Stress Variability}

[35] The subseasonal variability of upwelling-favorable wind stress over the region of interest is described using the first EOF of subseasonal wind stress anomalies. The wind stress first EOF explains $53 \%$ of the total subseasonal wind stress variance. Its spatial pattern (Figure 6a) indicates wind stress anomalies of the same sign over the entire region with upwelling-favorable south-east (upwelling- unfavorable north-west) direction for positive (negative) anomalies. The maximum amplitude of anomalies is found in front of Lüderitz corresponding to the mean position of the core of the atmospheric coastal jet favorable to upwelling [Nicholson, 2009]. A smaller local maximum of anomalies is observed in the Cape Frio area, as well near the coast. It is not surprising that the time series associated with this dominant mode of wind stress variability is significantly correlated with the time series associated with the dominant mode of SST variability (Figure 2a) that represents offshore signature of coastal upwelling. The maximum correlation of 0.52 between the SST PC1 and wind stress PC1 is found when wind stress leads SST by 1 day. Note that similar patterns for wind stress and SST are associated with the dominant mode of covariance between wind stress and SST subseasonal anomalies, obtained based on a singular value decomposition (not shown).

[36] The wavelet analysis of the wind stress PC1 indicates, however, that despite this significant correlation, the subseasonal variability of wind stress has different spectrum characteristics from the SST. Thus, as illustrated by the wind stress global NWPS (Figure 6b), the greatest amount of the wind stress energy is confined in the submonthly band, which represents $90 \%$ of the total power of the spectrum and peaks at $\sim 7$ days. Moreover, the climatology of the NWPS (Figure 6c) reveals that this submonthly variability is larger during austral winter months, from June to October, and, therefore, is out of phase with the seasonal cycle of the SST submonthly variability shown in Figure 
(a)

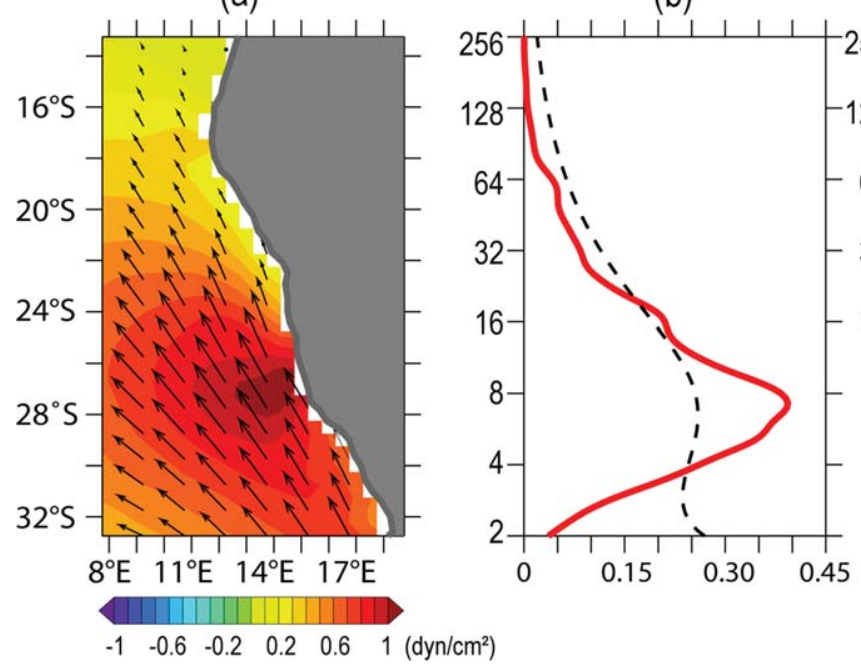

(c)

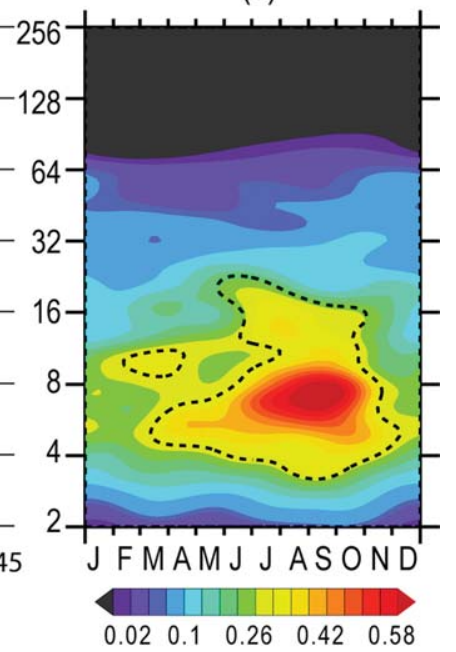

Figure 6. First mode of the bivariate EOF analysis of the subseasonal anomalies of the meridional and zonal wind stress: (a) Spatial pattern $\left(\mathrm{dyn} / \mathrm{cm}^{2}\right)$ showing wind stress vectors (arrows) and wind stress amplitude (color shading), (b) global Normalized Wavelet Power Spectrum (NWPS), and (c) climatology of the NWPS for the wind stress PC1. Black dashed line in Figures $6 \mathrm{~b}$ and $6 \mathrm{c}$ shows the $90 \%$ confidence level (see section 2 for the definition of the level of significance). Figure $6 \mathrm{~b}-6 \mathrm{c}$ are in nondimensional units.

$2 \mathrm{~d}$. The intraseasonal oscillations represent only $9 \%$ of the total variance of the PC1 time series and are not statistically significant. It is important to note however that a small well-defined energy peak is observed around 60 days. It is more energetic in summer than in winter.

[37] Another particular feature of the wind stress PC1 in comparison with the SST PC1 is that it is significantly positively skewed reflecting a larger amplitude (in absolute value) of the upwelling-favorable winds than upwellingunfavorable winds in the submonthly frequency band: the skewness coefficient of the 2-30 days band-pass filtered wind stress PC1 is 0.7 , whereas within the $30-90$ day $^{-1}$ frequency band, it is nearly symmetric (skewness coefficient is -0.04). Note that the standard deviation of the 30-90 days filtered wind stress PC1 $\left(0.26 \mathrm{dyn} / \mathrm{cm}^{2}\right)$ is almost four times smaller than the standard deviation of the 2-30 filtered wind stress PC1 $\left(0.94 \mathrm{dyn} / \mathrm{cm}^{2}\right)$, consistently with the Global NWPS.

\subsection{Subseasonal SST Response to Wind Stress Forcing: Seasonal Dependence}

[38] Given that there is no apparent concordance between the climatological spectra for SST PC1 (Figure 2d) and for wind stress PC1 (Figure 6c) with regards to the dominant frequencies and seasonal cycle, we now investigate the correlation between SST and wind stress as a function of frequency and calendar month. This consists in calculating the climatological running correlation between SST PC1 and wind stress PC1 separately for the two regimes. First, following the analysis of SST variability presented in section 3, we separate the submonthly and intraseasonal wind stress variability by applying the corresponding band-pass Lanczos filters (2-30 days and 30-90 days, respectively) to the wind stress $\mathrm{PC} 1$. Then, we use a running window of 60 days for the submonthly regime and of 180 days for the intraseasonal regime to calculate the running correlation between the filtered SST series and the corresponding filtered wind stress series. Inside of each running window, for both submonthly and intraseasonal regimes, the maximum correlation coefficient was estimated allowing lags from -20 to 20 days (positive lag means that the wind leads SST). The maximum correlation, as well as the associated lag, was retained to estimate the monthly climatological correlation and associated climatological lag. The climatological correlation for a given month is considered significant, if $99 \%$ of the maximum correlation coefficients obtained in the running windows over the corresponding months are significant at the 0.01 level.

[39] Figure 7a displays the climatological running maximum lag-correlation (with its associated lag) between SST and wind stress for the two dominant regimes of variability. Both regimes show a strong relationship with correlation exceeding 0.55 for all calendar months. The positive lag observed for both regimes indicates that the wind stress leads the SST. The submonthly regime exhibits two seasonal maxima (i.e., a marked semiannual cycle) with a high correlation of approximately 0.7 : from January to March and then in September to October. The correlation is the weakest during winter months from May to July. The wind stress leads the SST by 1 day all year round. For the lowerfrequency intraseasonal regime, a high correlation (larger than 0.7 ) is observed during the extended summer, from November to April, while lower correlation of approximately 0.6 characterizes the extended winter, from May to October. Figure 7a indicates that during December to January, when the correlation is maximal and exceeds 0.8 , wind stress leads SST by 7 days. During the other calendar months, the lag varies from 4 to 7 days with wind stress leading. A comparable seasonal dependency of the SST- 
(a)

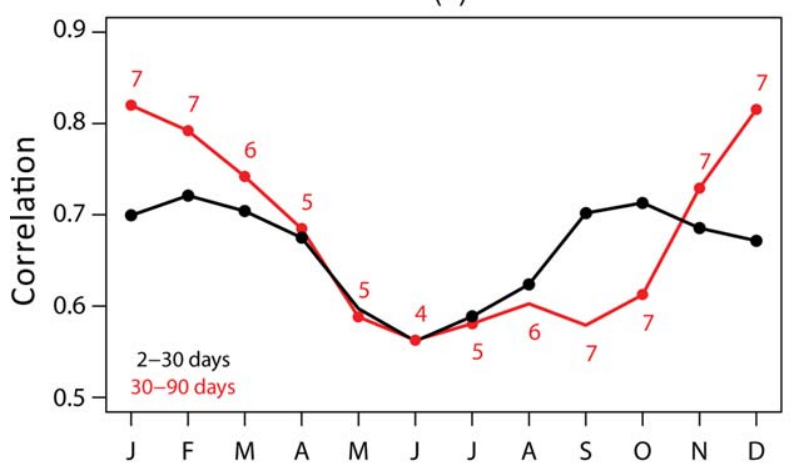

(b)

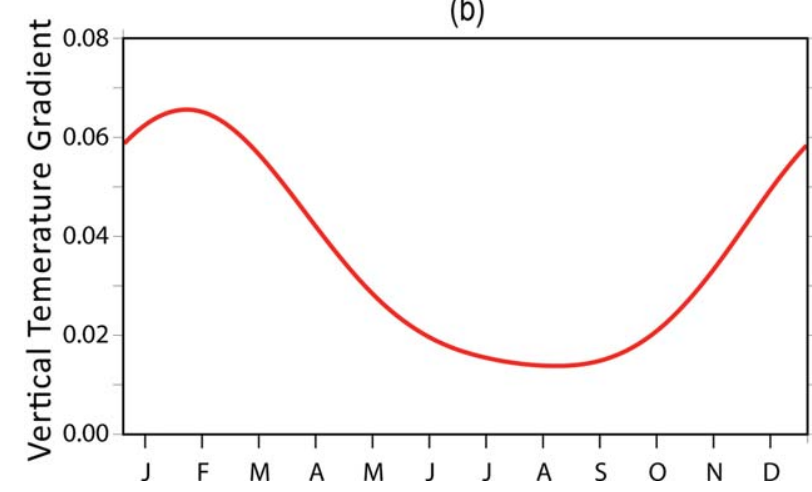

Figure 7. (a) Climatology of the running maximum lagged-correlation between the SST PC1 and the wind stress PC1 for the submonthly (black line) and intraseasonal regime (red line). For the submonthly regime, the lag between wind stress and SST is 1 day (wind stress leads) all year round. For the intraseasonal regime, the corresponding lags are indicated for each climatological month by red numbers. Dots indicate the climatological months for which $99 \%$ of the running maximum lagged-correlation values are statistically significant at the 0.01 level. See text for the details. (b) Climatology of the near-surface VTG $\left({ }^{\circ} \mathrm{C} / \mathrm{m}\right)$ averaged between $30^{\circ} \mathrm{S}$ and $16^{\circ} \mathrm{S}$ over $100 \mathrm{~km}$ off the coast.

wind stress relationship at the intraseasonal scale with maximum correlation in summer and minimum correlation in winter was found in the Humboldt upwelling system off Peru [Dewitte et al., 2011], although with a weaker correlation for all calendar months. The lower values of correlation there can be explained by the fact that Dewitte et al. [2011] did not consider time lags in their analysis.

[40] In order to better interpret the seasonal dependence of the relationship between the wind stress forcing and the SST response at subseasonal time scales in the central Benguela upwelling system, we consider the simple SST equation, where the rate of SST change within the mixed layer is assumed to result principally from the anomalous vertical advection of mean temperature, that is

$$
\frac{\partial T}{\partial t}=-\tilde{w} \frac{\partial \bar{T}}{\partial z}
$$

where $\tilde{w}$ and $\left(\frac{\partial \bar{T}}{\partial z}\right)$ stand for the vertical velocity anomaly and mean vertical temperature gradient, respectively. This approach is motivated by the previous results that show that the upwelling variability is to a large extent wind driven. Note, however, that the equation (1) could not fully account for the rate of SST changes and that other processes may be at work. For instance, Renault et al. [2009] showed that during a coastal jet event off Central Chile, the SST anomaly could result from a combination of processes including horizontal and vertical advection and heat flux forcing. Here, we use the simplified model for simplicity and to avoid difficulties associated with the estimation of other processes from observed data. Within such an assumption, the change in SST $(\partial T / \partial t)$ depends on the upwelling rate $\tilde{w}$ and is modulated by mean vertical stratification $\left(\frac{\partial \bar{T}}{\partial z}\right)$ that may evolve seasonally. Vertical velocity $\tilde{w}$ is induced by the along shore wind stress anomalies $\tilde{\tau}$ and can be estimated from Ekman transport. Assuming that upwelling is taking place within a narrow coastal fringe with length scale $L_{U}$ (in the Benguela upwelling system $L_{U}$ is about $5 \mathrm{~km}$ [Marchesiello and Estrade, 2010]): $\tilde{w}=$ $\frac{\tilde{\tau}}{\rho f L_{U}}$, where $\rho$ and $f$ denote the seawater density and Coriolis parameter, respectively. Consequently, $\frac{\partial T}{\partial t}=-\frac{\tilde{\tau}}{\rho f L_{U}} \cdot \frac{\partial \bar{T}}{\partial z}$. This formulation is consistent with the 1-D upwelling model proposed by Alory et al. [2006], although we do not consider here the impact of the heat flux term on the rate of SST change. Noteworthy, although the OI TMI data are not available in a narrow near-coastal band (cf. section 2.1), processes captured by the first EOF of SST subseasonal anomalies (Figure 2) may reflect primarily the coastal divergence of the seaward Ekman currents. Therefore, the equation (1) is thought to be relevant for the interpretation of the features derived from satellite observations.

[41] In this formulation, the mean vertical stratification, i.e., vertical temperature gradient (VTG), can be interpreted as the efficiency by which wind stress can lead to change in SST. This leads us to examine the seasonal cycle of the nearsurface VTG. Based on the CARS 2009 monthly climatology [Ridgway et al., 2002] of the observed ocean temperature (available at http://www.marine.csiro.au/ dunn/cars2009), we define the near-surface VTG as the difference between the SST and the temperature at $50 \mathrm{~m}$ depth. Figure $7 \mathrm{~b}$ illustrates that the VTG observed along the coast is maximum in summer and minimum in winter, with a ratio between maximum and minimum reaching $\sim 4$. This suggests that the semiannual cycle in the correlation between SST and wind stress observed for the submonthly regime (Figure 7a) reflects a seasonal modulation of the efficiency of the vertical advection process under seasonally varying wind-stress submonthly variability. Indeed, from January to March the variability of wind stress is the weakest (Figure 6c) but its efficiency, in terms of its impact on the SST, is the highest, due to the increased VTG. By contrast, in September-October the smallest VTG is compensated by the strongest wind stress variability. Yet, for the intraseasonal regime, given that the wind stress variability is rather weak over the 30-90 days band all year round, the strength of the relationship between the SST and wind stress is mainly modulated by the VTG. Indeed, the climatological correlation between SST and wind stress at intraseasonal time scales (Figure 7a, red line) follows exactly the seasonal cycle of the VTG (Figure 7b).

[42] The seasonal cycle of the VTG in the upper oceanic level is driven, to a large extent, by solar radiation and by 
mean wind stress that modulates vertical advection and vertical mixing. Over the Central Benguela region (south of $22^{\circ} \mathrm{S}$ ), both the solar radiation and mean wind stress are stronger in summer and weaker in winter. Interestingly, the subseasonal wind variability, that may also have a strong impact on the vertical mixing, is larger in winter and smaller in summer. Thus, the variability of wind stress at submonthly scales could partly contribute to modulate its efficiency on SST change at the seasonal time scale.

\subsection{Regional Wind Stress Composites}

[43] To investigate further the relationship between SST and regional wind stress the lag-composites of wind stress anomalies corresponding to the two subseasonal regimes are examined based on the respective filtered SST PC1. The wind stress composite analysis will allows us, in particular, exploring the linearity of the SST response to wind stress forcing by comparing the two regimes of variability, as well as the cold and warm events.

[44] Figure 4 presents the lagged composites of windstress submonthly anomalies for wind stress amplitude and wind stress vector calculated for the submonthly cold SST events. The wind stress evolution is consistent with upwelling intensification events at the submonthly scale. At lag -4 , the wind is calm. In the following day, it increases slightly off Cape Frio and at lag -2 days the upwellingfavorable wind stress anomaly prevails over the entire region. It reaches its maximum at lag -1 day, consistently with the lag found for the climatological runningcorrelation between subseasonal wind stress and SST (Figure 7a). This wind stress anomaly has a south-east direction and magnitude of $0.94 \mathrm{dyn} / \mathrm{cm}^{2}$ on average over the region. The wind stress maximum of $1.66 \mathrm{dyn} / \mathrm{cm}^{2}$ is observed just near the coast in the Lüderitz area. At the peak phase of SST cold event, at lag 0 , the wind stress maximum shifts southward and offshore from the Lüderitz area, while over the northern part of the region, particularly over Cape Frio, the wind stress weakens to normal. At lag +1 day, when the SST cold anomaly is still strong, anomalous wind stress becomes northwest all along the coast, except over its most southern part. At lag +2 days, an upwelling-unfavorable wind stress anomaly definitively prevails over the region. Similarly, for the warm SST events, the wind evolution (not shown) is consistent with submonthly upwelling weakening. For instance, at lag -1 day, when north western wind stress is the strongest, the wind stress magnitude is $-0.43 \mathrm{dyn} / \mathrm{cm}^{2}$ on average over the region and $-0.76 \mathrm{dyn} /$ $\mathrm{cm}^{2}$ locally in the Lüderitz area. Thus, the absolute value of wind stress anomaly for the warm events is almost two times weaker than for the cold events, although the corresponding SST anomalies have approximately the same amplitudes. This can be seen in Figure 8 that shows the ratio between SST (wind stress) submonthly composites for cold and warm SST events for the lag 0 days ( -1 day) that corresponds to the maximum SST (wind stress) anomalies.

[45] For the lower-frequency intraseasonal regime, the wind evolution for cold (Figure 5) and warm (not shown) events is characterized by spatial features resembling those for the submonthly regime. At the initiation phase of the event, at lag - 15 days, a corresponding wind stress anomaly (upwelling favorable for cold events and upwelling unfavorable for warm events) appears in the northern part

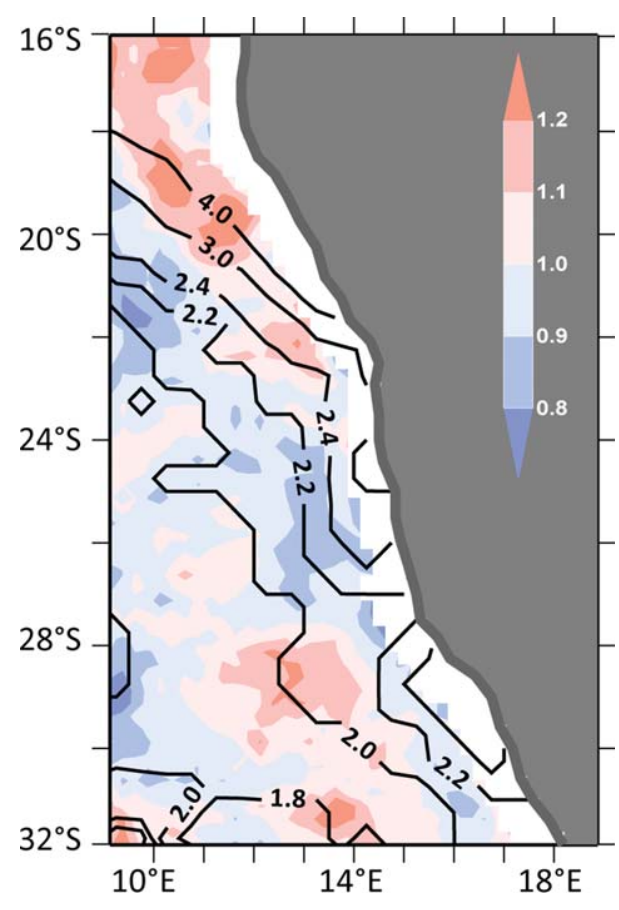

Figure 8. Ratio between the composite of submonthly SST anomalies at lag 0 days for SST cold events and the corresponding composite for SST warm events (colors shading, ${ }^{\circ} \mathrm{C}$ ). Contours show the respective ratio for the composites of submonthly wind stress anomalies at lag -1 day (Units: dyn $/ \mathrm{cm}^{2}$ ). Cold and warm events are defined based on the 2-30 day ${ }^{-1}$ band-pass filtered PC1 (Figure $3 a)$. Values for the ratio close to 1 means no asymmetry, whereas values for ratio larger than 1 indicate a positive asymmetry.

of the region. It develops during the following days and reaches its maximum at lag -7 days, consistently with the lag found for the climatological running correlation in summer (Figure 7a). Lag 0 is associated with a significant weakening of wind stress anomaly in the northern part of the region and with a shift of the core of anomaly southward in the southern part of the region. During the following days, the wind stress anomaly changes its direction to the opposite one, while the original SST anomaly persists during an additional week. Note that, contrary to the submonthly regime, the lower-frequency intraseasonal wind stress anomalies corresponding to cold and warm events are characterized by approximately the same magnitudes. For instance, at lag -7 days, the wind stress anomalies are 0.24 and $-0.23 \mathrm{dyn} / \mathrm{cm}^{2}$ on average over the region for the cold and warm events, respectively, with corresponding maxima in the Lüderitz area of 0.34 and $-0.41 \mathrm{dyn} / \mathrm{cm}^{2}$. Note that the wind stress anomalies for the lower frequency regime are weaker (about three times for the cold events and about two times for the warm events) than submonthly wind stress anomalies.

[46] It is now interesting to compare the magnitude of the SST and wind stress patterns as a function of the regimes. Whereas the SST anomalies have comparable amplitude for the two regimes, the corresponding wind stress anomalies for the submonthly time scale are larger than for 


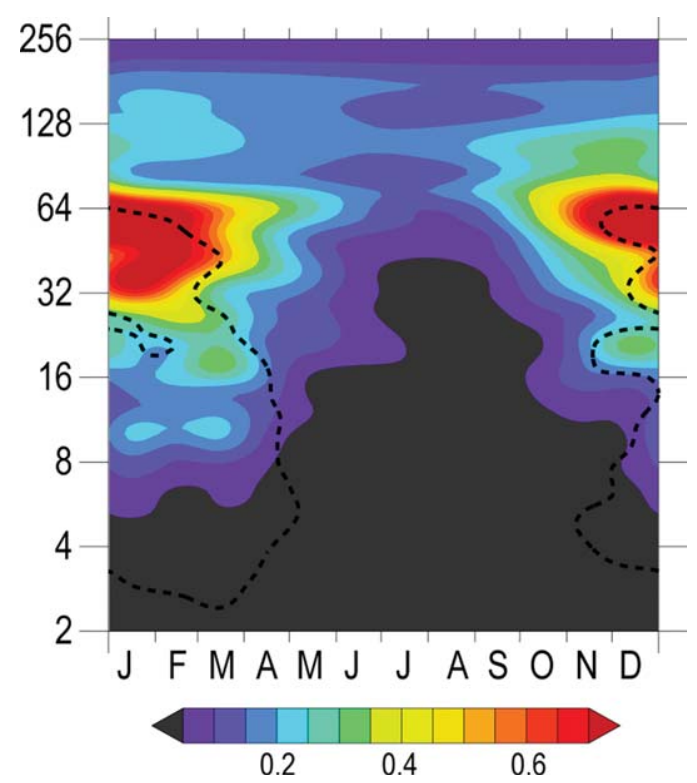

Figure 9. Climatology of the NWPS of the time series obtained by multiplying the wind stress PC1 by the seasonally varying VTG that determines the "efficiency" of wind stress in terms of its impact on the rate of SST change. For each frequency, the NWPS is multiplied by the corresponding period, accordingly to the equation (2) (section 4.3), and then normalized to have a total power within the spectrum (or, equally, the total variance of the reconstructed time series) of 1 . Black dashed line shows the $90 \%$ confidence level (see section 2 for the definition of the level of significance). Nondimensional units.

the intraseasonal time scales, by a factor of approximately 5 (for the maximum upwelling-favorable anomalies in the Lüderitz area, cf. Figures 4d and 5d). As mentioned above, assuming Ekman dynamics, the rate of SST changes is controlled by the vertical advection process and is proportional to the magnitude of the alongshore wind stress anomalies. Under an oscillating regime $\tilde{\tau}=\|\tilde{\tau}\| e^{i \omega t}$, for a given frequency, the amplitude of SST changes is given by:

$$
\Delta T \sim \frac{1}{\omega}\|\tilde{\tau}\| \frac{\partial \bar{T}}{\partial z}
$$

[47] This indicates that the ratio between the wind stress and SST anomaly amplitudes will be proportional to the frequency of the considered oscillation. Our results are consistent with the proposed conceptual model since the ratio of the dominant frequency of the two identified regimes, 61 and 11 days, respectively, is 5.5.

[48] In order to provide more evidence of the consistency of our results with the conceptual model, we calculated the NWPS of the time series obtained by multiplying the wind stress PC1 by the seasonally varying VTG. According to the equation (2), for each frequency the NWPS was scaled by the corresponding period. To be able to compare the NPWS with the NPWS of the standardized wind stress PC1 and SST PC1 (Figures 2d and 6c, respectively), it was normalized to have a total power within the spectrum of 1 . The resulting NWPS is shown in Figure 9. It highlights statisti- cally significant strong power occurring in summer season with most of the energy concentrated in the intraseasonal frequency band (30-90 days), consistently with the NWPS of the SST PC1 (Figure 2d). Although this NPWS shows smaller energy in the submonthly frequency band relative to the NWPS of the SST PC1, a significant peak at approximately 11 days can be clearly identified, consistently with the frequency characteristics of the SST PC1. This result confirms our interpretation of the Figure 7 (section 4.2) since it clearly evidences that the VTG represents the "efficiency" by which wind stress modulates the subseasonal SST changes at the seasonal scale.

[49] We now discuss the limitations of the conceptual model proposed to interpret our results that accounts only for the anomalous vertical advection of mean temperature. The limitations are mainly related to the fact that more processes other than the vertical advection may contribute to SST subseasonal fluctuations and may be also relevant to explain the seasonal cycle of the observed wind-SST relationship at the subseasonal scale. For instance, the insufficient energy in the NPWS reconstructed from the wind stress PC1 based on the conceptual model (Figure 9) over the submonthly band, in particular during the SeptemberOctober-November season, can be attributed to seasonally dependent processes not considered in equation (2). For instance, the contribution of heat flux forcing to the rate of SST change is explicitly modulated by the seasonally varying mixed layer depth (cf. section 6.2 for a discussion on the role of heat flux), and vertical mixing is also seasonally dependent.

[50] Another limitation of the proposed linear model is that it cannot explain the difference in asymmetry of the SST and wind stress anomaly composites for cold and warm events, observed at the submonthly time scale. Indeed, the corresponding cool and warm SST anomalies have comparable amplitudes, whereas the upwellingfavorable wind anomalies are significantly larger than the upwelling-unfavorable wind anomalies in absolute value (Figure 8). Such a nonlinear characteristic of the relationship between SST and wind stress at the submonthly time scale may be understood in terms of the nonlinear response of mixing to the winds that modulates the rate of SST changes. In particular, upwelling-favorable wind anomalies participate to increasing the mixing induced by the mean upwelling-favorable wind more than the upwellingunfavorable wind anomalies would reduce it, which results in an asymmetrical change in VTG at subseasonal time scales, and hence in SST. Restratification process associated with mixed-layer eddies [Fox-Kemper and Ferrari, 2008] may also be at work to explain this asymmetry feature (see for instance Renault et al. [2009] for its role during a coastal jet event off Central Chile).

[51] It is also interesting to note that the oscillation regime for a given frequency in the equation (2) implies a $90^{\circ}$ out of phase between the wind stress and SST. This means that for the dominant 11 days and 61 days oscillations the wind stress should lead SST by $\sim 3$ and $\sim 15$ days, respectively. In order to interpret the difference between these theoretical values of lags and the lags observed for the submonthly (1 day lag, cf. Figures 4 and 7) and intraseasonal (7 days lag, cf. Figures 5 and 7) regimes, one should keep in mind that the observed dominant regimes do 
(a) Cold, -3 days

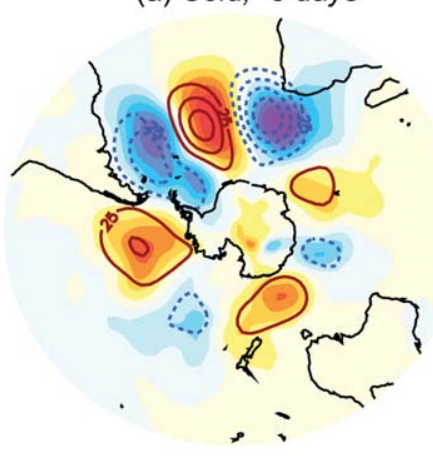

(d) Cold, 0 days

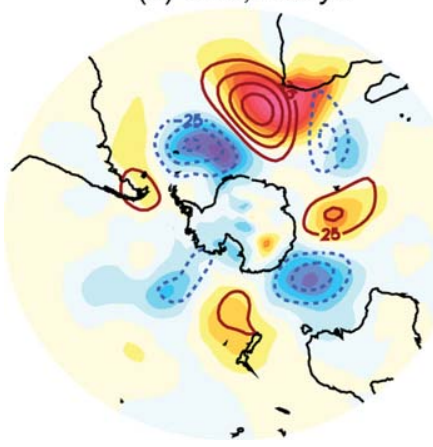

(b) Cold, -2 days

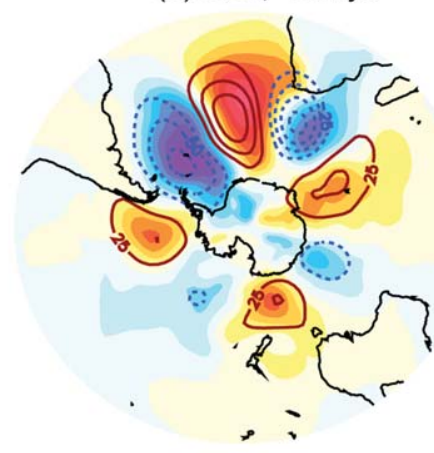

(e) Cold, +1 day

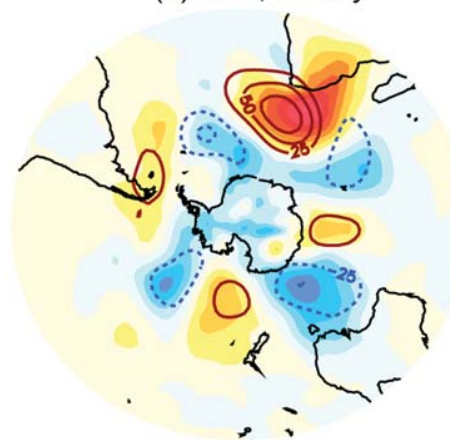

(c) Cold, -1 day

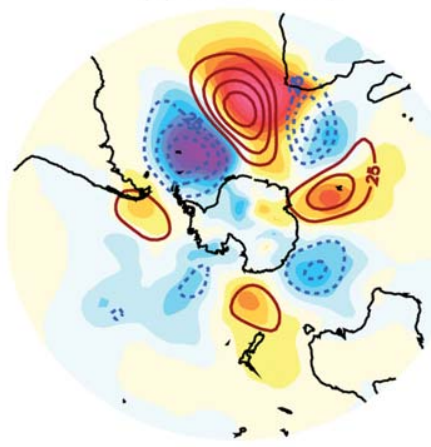

(f) Warm, -1 day

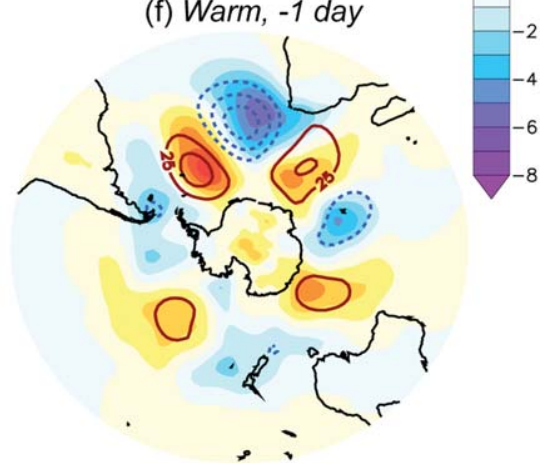

Figure 10. (a-e) Time-lagged composites of the submonthly anomalies of SLP (color shading, hPa) and $500 \mathrm{hPa}$ geopotential height (contour, gpm) for the SST cold events identified in Figure 3a, for the lags (a) -3 days, (b) -2 days, (c) -1 day, (d) 0 day, (e) +1 day, and (f) as in Figure 10c but for the SST warm events. Contours are drawn every $25 \mathrm{gpm}$, with the zero line omitted (blue and red contours indicate cyclonic and anticyclonic anomalies, respectively).

not represent mono-frequency oscillations with the period 11 and 61 days but are associated with a broad spectrum of energy in the corresponding frequency bands (Figure 2c). The slight asymmetry observed between the amplitudes of cold and warm events and between the lengths of the onset and decay phases of events may also explain the deviation from the quadrature relationship. Moreover, the reduction in phase-lag relationship between wind stress and SST is certainly due, at least partly, to other processes not considered in equation (2). In particular, negative feedback processes like solar heat flux forcing, mixing, or restratification processes may be accounted for by adding a linear damping term in equation (2), which would imply a reduction of the quadrature between SST and wind stress.

\section{Link with Large-Scale Circulation}

[52] In this section, we examine the link between winddriven subseasonal fluctuation of SST and large-scale atmospheric circulation based on the same composite method as in sections 3 and 4. For this purpose, the anomalies of sea level pressure (SLP) and geopotential height at $500 \mathrm{hPa}(\mathrm{Z} 500)$ are examined in the submonthly and intraseasonal bands of frequencies. We are particularly interested here in verifying whether the two subseasonal regimes are associated with a same pattern of large-scale variability that manifests at both, the submonthly and intraseasonal time scale, or if two (or more) different large-scale phenomena are at play for wind-driven subseasonal SST variability.

\subsection{Submonthly Regime}

[53] Figure 10 presents the lag-composites of the SLP and Z500 for submonthly events. There is a clear evidence that submonthly regime is related to eastward propagating disturbances at the midlatitudes associated with the wave number 4 pattern [Kidson, 1991; Kiladis and Mo, 1998]. The propagation presents in general a coherent pattern of circulation from surface to higher level, with a slight westward tilt with height indicating some baroclinicity of propagating structure.

[54] Composite cold events (Figures 10a-10e) in the central Benguela region are associated with a well-defined extratropical wave train over the Eastern South-East Pacific and South Atlantic. In particular, three days before the cold event a surface high (midlevel ridge) bounded by two surface lows (midlevel troughs) at its east and west sides is situated over the Central Southern Atlantic. At lag -2 days, the midlevel ridge and surface high amplify and the latter extends northward and toward the African continent. During this and the following day, the surface high pressure with the midlevel ridge axis at $500 \mathrm{hPa}$, just west of the surface high center, moves to the South East Atlantic. Thus, the south eastern wind associated with the north eastern flank of the surface anticyclone favors the development of an alongshore positive wind anomaly over the Benguela upwelling system (as seen in Figures 4c-4d). At lag 0, the surface anticyclone under a midlatitude ridge, migrating eastward, starts to surround the continent, so that only the 
(a)

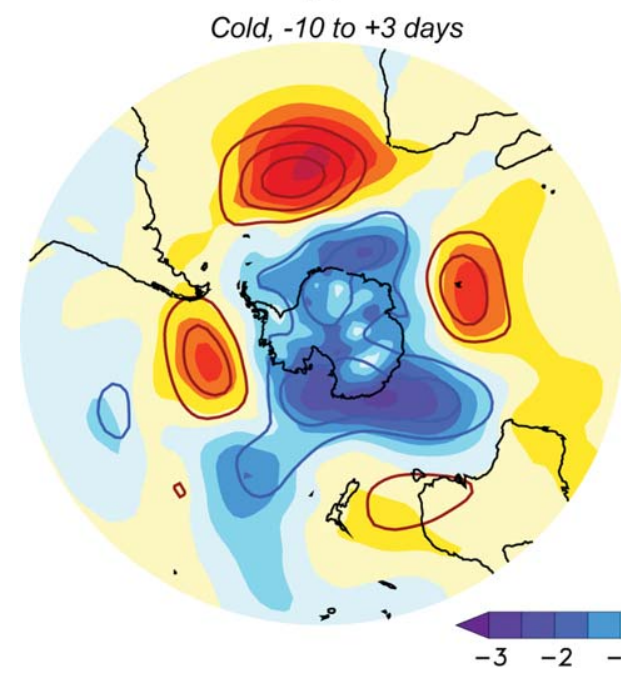

(b)

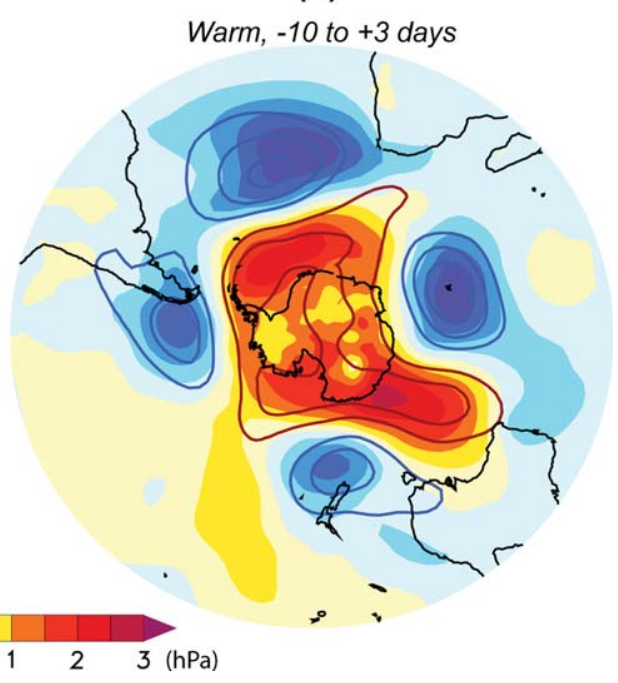

Figure 11. Composite of the intraseasonal anomalies of SLP (color shading, hPa) and $500 \mathrm{hPa}$ geopotential height (contour, gpm) for the SST intraseasonal (a) cold and (b) warm events identified in Figure $3 \mathrm{~b}$, averaged over the lags from -10 days to +3 days. Contours are drawn every $10 \mathrm{gpm}$, with the zero line omitted (blue and red contours indicate cyclonic and anticyclonic anomalies, respectively).

southern part of the Benguela system remains under the influence of high-pressure system. Note that the low pressure system that follows behind, moves in the southeast direction, approaching Antarctica, and weakens. During the following days, the anticyclone weakens and drifts around the tip of Africa to the Indian Ocean, whereas the surface low and trough aloft, which follow behind, dissipates.

[55] The large-scale circulation patterns associated with the warm SST subseasonal events also present a wave-like propagation (not shown), although this wave number 4 pattern has smaller amplitudes than for the cold SST events. This pattern shows the strongest anomaly corresponding to a low pressure system that crosses the South-Eastern Atlantic from west to east during 4 days, from 3 days before the event and until the event peak phase (cf. Figure 10f for lag -1 day). This negative anomaly has weaker absolute amplitude and smaller spatial extension than the corresponding positive anomaly associated with cold wind-driven SST events. Consequently, the absolute value of wind anomaly in the central Benguela upwelling system associated with north western winds, blowing along the north eastern flank of the surface low, is weaker than the corresponding value observed during the cold events. This is a rather expected result given that the dominant mode of wind stress is characterized by a strong positive asymmetry (section 4.1). Investigation of mechanisms that may explain the differences in the intensity between high-pressure and low-pressure anomalies associated with the South Atlantic wave train impacting the central Benguela region would require a detailed analysis of the regional atmosphere dynamics and is beyond the scope of the present paper.

\subsection{Intraseasonal Regime}

[56] We now examine the composites of large-scale circulation associated with the intraseasonal wind-driven SST variability in the central Benguela upwelling system. Given that all strongest intraseasonal SST events occur from No- vember to April (Figure 3b), the large-scale atmospheric patterns presented in this subsection are representative of the extended summer season. For simplicity, we show only the lag-composites for cold (warm) events averaged between lag -10 days and +3 days, which corresponds to the period when the regional wind stress composites present upwelling-favorable (-unfavorable) anomalies.

[57] Figure 11a shows the averaged composite of SLP and $500 \mathrm{hPa}$ height for the cold events. As for submonthly regime, it is characterized by an enhanced surface highpressure anomaly with a midlatitude ridge which center is situated just west of the center of the surface high over the South East Atlantic. This high-pressure system is associated with the wave number 4 pattern in the middle latitudes that propagates slowly eastward at average rate of $2^{\circ}$ longitude per day at $45^{\circ} \mathrm{S}$ (not shown).

[58] A striking feature of the intraseasonal composite is a pronounced negative surface pressure anomaly over Antarctica that appears approximately 10 days before the event and last during the two following weeks. A similar negative anomaly of geopotential height is found at $500 \mathrm{hPa}$ (Figure $11 \mathrm{a}$, contour) and $200 \mathrm{hPa}$ (not shown), suggesting an impact of the intraseasonal component of the Antarctic oscillation (AAO) [Rogers and van Loon, 1982; Pohl and Fauchereau, 2012], also called Southern Annular Mode or High Latitude Mode. The evolution of the SLP and Z500 composites (not shown) can be interpreted as an interchange of air mass between middle and high latitudes, a well-known feature of the AAO. Thus, approximately 2 weeks before the peak phase of event, the low pressure centers of the wave number 4 pattern in the middle latitudes start to migrate poleward and then, 1 week before the event, merge into a negative anomaly over Antarctica, while, approximately 3-5 days after the peak phase, the negative anomaly over Antarctica weakens and split up into separated lows migrating northward. The corresponding composites for the intraseasonal warm events are characterized by 
similar SLP and Z500 anomalies, in terms of spatial and temporal evolution, as well as amplitude, but with opposite sign (cf. Figure 11b for composites averaged between lag -10 days and +3 days).

[59] Although most studies aimed at understanding Southern Hemisphere atmospheric dynamics have focused on the interannual component of the AAO, a recent study by Pohl et al. [2010] reveals that the preferred range of variability of the AAO corresponds to the intraseasonal time scale, with $34 \%(62 \%)$ of the total AAO variability confined in the 35-63 (18-117) days ${ }^{-1}$ frequency band. Note that Kidson [1991] analyzed the intraseasonal (10-50 days) variations in the Southern Hemisphere atmospheric circulation over the period 1980-1988 and showed that the High Latitude Mode represents the dominant mode of the subseasonal variability (first EOF of Z500) during extended summer, consistently with the season of the maximum intraseasonal SST variability in the central Benguela system. Pohl et al. [2010] showed that the AAO can have a strong impact on the regional climate variability in the Southern Hemisphere, in particular over the southern Africa region. It has been suggested that, at the interannual time scale, the impact of the AAO on the southern Africa seems to be a statistical artifact since the correlation between the AAO and regional climate variables becomes very weak once the influence of El Niño Southern oscillation (ENSO) is removed (cf. Pohl et al. [2010] for rainfall and Rouault et al. [2010] for SST). In contrast, at the intraseasonal time scale, the AAO has been shown to impact significantly rainfall amount over this region, without interference with other modes of variability [Pohl et al., 2010]. Our study reveals that the intraseasonal component of the AAO also influences the intraseasonal wind-driven SST variability in the central Benguela upwelling system. Given that the AAO itself is affected by other climate modes (cf., for instance, Carvalho et al. [2005] for the link with the MJO and L'Heureux and Thompson [2006] for the impact of ENSO), this result suggests a possible mechanism of the modulation of the intraseasonal variability of the central Benguela upwelling by the corresponding climate modes at their respective time scales.

\section{Discussion}

[60] We have investigated the SST subseasonal variability in the central Benguela upwelling system as observed from satellite observations. Our results showed that it shares many common features with the one observed in the Humboldt upwelling system [Renault et al., 2009; Dewitte et al., 2011]. In particular, two dominant regimes of variability corresponding to 2-30 days and 30-90 days, respectively, and modulated, to a large extent, by local wind stress through Ekman dynamics, were evidenced in both upwelling systems [Dewitte et al., 2011]. In the central Benguela system, the seasonality of the relationship between wind stress and SST for the submonthly (intraseasonal) regime has a marked semiannual (annual) cycle, which is explained in terms of the impact of seasonal change of the upper ocean stratification on the vertical advection process. Such seasonality of the "efficiency" of the intraseasonal Ekman dynamics was also observed for the Humboldt upwelling system off Peru [Dewitte et al.,
2011] and off Central Chile [Renault et al., 2009], although the semiannual cycle was not detected for the submonthly time scales. The seasonality of the SST variability is suggested to be related to the seasonal cycle of the along-shore winds itself that modulates the local stratification through mixing, and thereby modulates the vertical advection process. Of course, there are significant differences between the central Benguela and Peru systems, and other processes may be at play to explain the change in stratification and/or such seasonality. Two processes are discussed in the following that may need to be considered to address further this issue. First, the connection with the intraseasonal equatorial oceanic Kelvin waves which may impact SST along the coast through mean vertical advection of anomalous temperature [Dewitte et al., 2011]. Second, the heat flux that represents a local forcing for the SST changes and may be connected to the variability of large-scale atmospheric circulation, as shown by $X u$ et al. [2005] for an offshore region in the northern Humboldt system.

\subsection{Oceanic Intraseasonal Equatorial Kelvin Waves}

[61] In the tropical Atlantic, the Equatorial Kelvin Wave (EKW) exhibits a significant activity at different time scales, ranging from intraseasonal [Han et al., 2008; Polo et al., 2008] and seasonal [Schouten et al., 2005] to interannual [Illig et al., 2004]. Linear theory states that part of the energy of the EKW is transmitted along the coast through Coastal Trapped Waves (CTW) south of a so-called critical latitude that is a function of the dominant frequency of the wave [Clarke and Shi, 1991]. Therefore, the processes associated with the transmission of the energy of the EKW along the coast and their impact on SST are also likely frequency dependant. For instance at seasonal to interannual time scales, the EKW propagation to the ABFZ can trigger strong warm SST anomalies in the Central Benguela through anomalous meridional advection of the warm Angolan water associated with an intensified geostrophic poleward transport resulting from interaction of the wave with the Angola current [Rouault et al., 2007; Rouault, 2012]. Such mechanism was also suggested to be at work for more episodic event like in April 1999 [Mohrholz et al., 2001; Doi et al., 2007], when a warm SST anomaly was observed up to $20^{\circ} \mathrm{S}$ [Rouault et al., 2003]. At intraseasonal time scales, the critical latitude is such that most of the energy is trapped south of $\sim 10^{\circ} \mathrm{S}$, implying finer latitudinal scales of variability and probably different advection processes than for seasonal and interannual time scales. As a consistency check, the critical latitude is estimated following Clarke and Shi [1991] for the first and second baroclinic modes (Figure 12, top, orange lines). It indicates that for the first mode IEKW, part of the incident subseasonal energy can radiate back to the offshore region as Rossby wave as far as $17^{\circ} \mathrm{S}$, while for the second baroclinic mode IEKW, the most energetic one [Illig et al., 2004], part of the incident subseasonal energy within the 2120 day $^{-1}$ frequency band is trapped along the coast south of $10^{\circ} \mathrm{S}$. CTW propagation affects the thermocline depth and Sea Surface Height (SSH) and, through induced anomalous vertical advection $\left(-\bar{w} \frac{\partial \tilde{T}}{\partial z}\right)$, can modulate near-coastal SST variability.

[62] In order to test the consistency of the IEKW forcing with the Central Benguela SST intraseasonal regime described in the paper, the frequency characteristics of the 
a) $\omega-\mathrm{k}$ IEKW m1

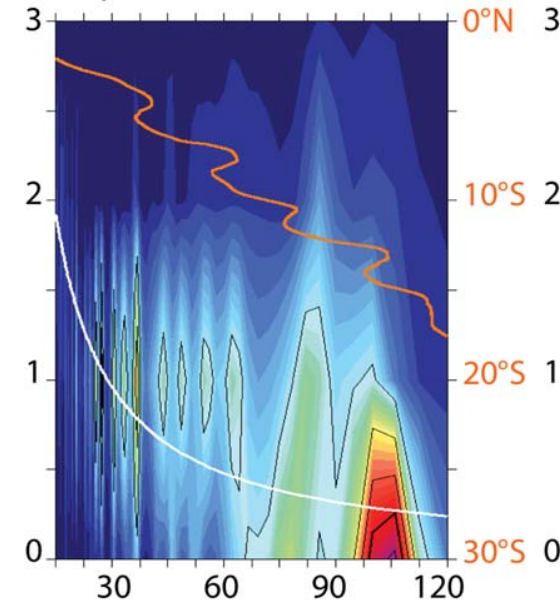

c) IEKW m1

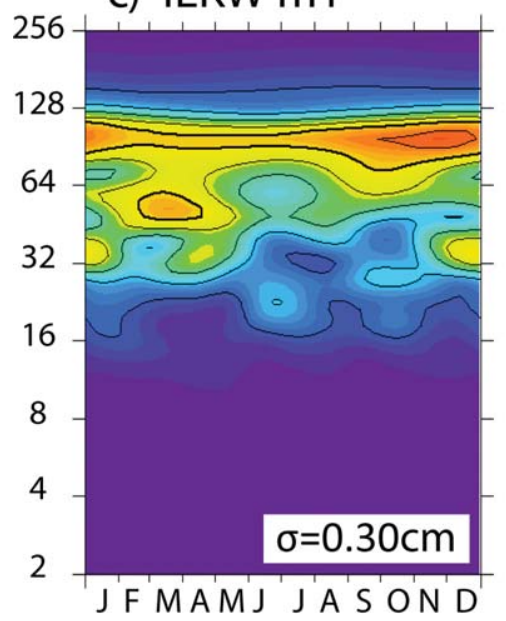

b) $\omega-\mathrm{k}$ IEKW m2

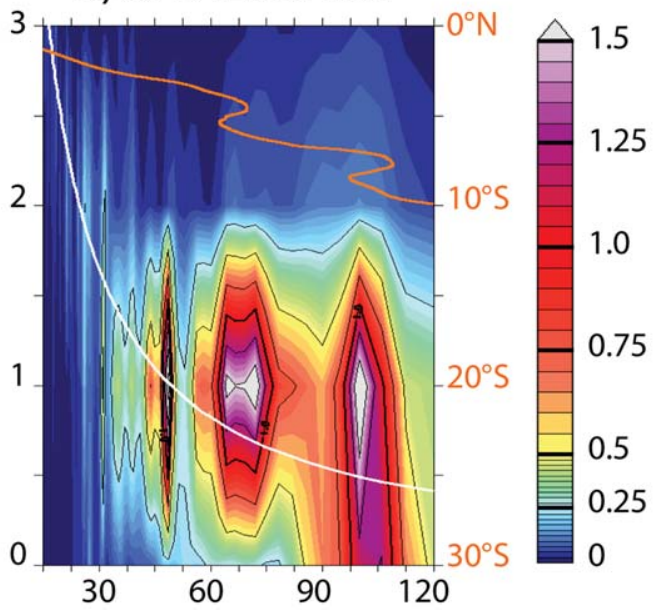

d) IEKW m2

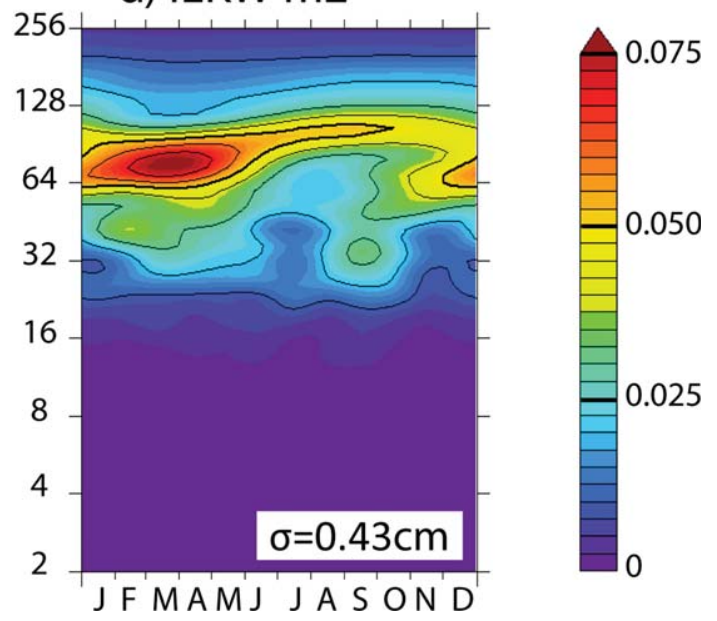

Figure 12. (top) Space-time power spectral density of the IEKW in the Tropical Atlantic for (a) the first and (b) the second baroclinic mode as function of zonal wave number (left scale) and period in days (bottom scale) over the period 2000-2008. Units are $\mathrm{cm}^{2}$. White lines indicate theoretical dispersion curves for Kelvin waves derived from the vertical mode decomposition based on the zonally averaged phase velocity. Orange line shows theoretical critical latitudes curves (right scale) as derived from the ETOPO topography following Clark and Shi [1991]. (bottom) Climatology of the NWPS for (c) the first and $(\mathrm{d})$ the second baroclinic mode contribution to the averaged IEKW over $\left(0-6^{\circ} \mathrm{E}\right)$. In Figures $12 \mathrm{c}$ and $12 \mathrm{~d}$ amplitudes of each baroclinic mode are first standardized by their standard deviation, indicated in the lower right corner.

IEKW in the Equatorial Atlantic over the period 20002008 is investigated from a space-time spectral analysis [Hayashi, 1982] applied to the contributions of the first two baroclinic modes IEKW. The resulting wavelengthfrequency diagrams (Figure 12, top) reveal the presence of long-wavelength $(k<2)$ IEKW with energy peak around 100 day $^{-1}$ for the first mode and at 47, 70, and 100 day $^{-1}$ for the second baroclinic mode. The dominant peaks of the IEKWs therefore match to some extent the intraseasonal peaks of the SST PC1 in the Central Benguela observed around 47, 61, and 97 days (Figure 2c). The climatology of the normalized wavelet power spectra of the IEKW in the eastern Atlantic (Figure 12, bottom) reveals further that both baroclinic modes experience relatively larger variability during the extended summer season than during extended winter. Thus, if the coastal trapped Kelvin waves propagate to the Benguela upwelling system, their impact on the SST variability should be more pronounced in summer due to two effects: the increasing activity of IEKW (Figure 12, bottom) and the enhanced stratification (Figure $7 \mathrm{~b}$ ). However, given the strong wind forcing south of the ABFZ, the coastal-trapped waves may have relatively less impact on the surface layer. As a matter of fact, we could not find any statistical relationship between the SST PC1 and the first two modes of the IEKW. For instance, the maximum lagged correlations between the SST PC1 and the IEKWs at $6^{\circ} \mathrm{E}$ (considering a lag between 0 and 60 days, with the IEKW leading the SST PC1) are not statistically significant. This is consistent with the results of Polo et al. [2008] who examined intraseasonal Kelvin-like propagations along the southwest African coast, based on altimetric data with a $0.5^{\circ}$ resolution over 
the period 1992-2000, and showed that they can be detected only as far as $12-15^{\circ} \mathrm{S}$. The authors hypothesize that the coastal wave signal may vanish south of the ABFZ since in this region a share of the energy of the propagating waves is strongly dissipated due to the outcropping isopycnals associated with the upwelling regime. They also emphasize that the resolution of the data does not allow accurate detection of the coastal trapped waves further poleward, which is also a limitation encountered in our study since the OI TMI SST is not available near the coast.

[63] In summary, despite the comparable seasonality and time-frequency characteristics of the IEKW activity and the SST intraseasonal variability off central Benguela, there is no evidence that the EIKW participate to the intraseasonal regime described in this paper. Further investigation using near-coastal surface (or subsurface) data from observations and/or high-resolution modeling is needed to address this issue.

\subsection{Heat Flux Forcing}

[64] Although we do not consider in this study the role of the heat flux in the central Benguela upwelling system, it may represent an important local forcing for the SST fluctuation (cf. Renault et al. [2009] for coastal jet events off Central Chile) and affect the seasonal cycle of the observed wind-SST relationship at the subseasonal scale. To evaluate the contribution of the net heat flux term to the rate of SST subseasonal change, we calculated the time-lagged composites of the net heat flux for the submonthly and intraseasonal events based on the latent, sensible, longwave, and shortwave heat issues from the NCEP reanalysis and following the same method as for the SLP and Z500 composites (cf. section 5). Our results suggest that although the net heat flux amplifies the dynamical effect of the wind, its contribution is not dominant for the change of SST at the subseasonal scale (not shown). For instance, for the submonthly composite cold event, assuming a constant mixed layer depth of $50 \mathrm{~m}$, the net flux contributes to cool the SST at the rate of $\sim 0.025^{\circ} \mathrm{C} /$ day, on average over the central Benguela region (estimated for the lag $=-1$ day), whereas the observed SST cooling is $\sim 0.4^{\circ} \mathrm{C}$ /day (Figure 4d). The NCEP reanalysis data suggest that this contribution is mainly due to the latent heat flux and, in to a much smaller extent, to the sensible flux. Note, however, that the NCEP reanalysis shows relatively large biases in the shortwave flux over the Benguela region that are due to an underestimation of total cloud fraction [Bedacht et al., 2007]. Indeed, the eastern boundary upwelling systems are characterized by the widest persistent low-level stratocumulus cloud cover that, reflecting the solar radiation, has a net cooling effect on the ocean surface [Klein and Hartman, 1993]. Xu et al. [2005] analyzed intraseasonal low cloud variability over the southeast Pacific stratus cloud deck (an offshore region in the northern Humboldt system extended over $10^{\circ}-25^{\circ} \mathrm{S}, 80^{\circ}-100^{\circ} \mathrm{W}$ ), based on observational data, and indicated a negative correlation between local SST and low-level clouds with the maximum absolute value of correlation at lag 1 or 2 days with cloud leading SST. They further suggest, however, that the response of SST can be only partly explained by a direct effect of changes in cloud cover and is rather due to an ensemble of processes associated with subseasonal cloud events. Inter- estingly, these events are found to be related to a strengthening of the South Pacific anticyclone associated with eastward propagating atmospheric disturbances in the midlatitudes corresponding to wave number 3 or 4 . We have shown in section 5 that the increase of upwelling-favorable wind in the central Benguela upwelling system at subseasonal scales is associated with similar large-scale atmospheric phenomenon: an intensification of the southeast Atlantic high induced by a wave number 4 pattern. Therefore, it is possible that processes similar to those associated with increase of low clouds in the South East Pacific, are at play over the South East Atlantic during upwelling intensification events, and that the corresponding shortwave flux fluctuations may contribute to regional offshore SST cooling in the central Benguela upwelling system at the subseasonal scale, along with latent and sensible flux. In order to quantify the role of the observed low-level cloud to the SST variability relative to the roles of other forcings, a detailed heat budget analysis of the upper oceanic layer should be done. This needs to be addressed from high-resolution modeling and is beyond the scope of the present study.

\section{Summary}

[65] The SST variability at the subseasonal time scale in the central Benguela upwelling system is documented over the 10 years period from September 1999 to August 2009. Our analysis based on OI TMI observations indicate that the first EOF mode of subseasonal SST anomalies explains $32 \%$ of the total subseasonal variance over the region $32-$ $14^{\circ} \mathrm{S}, 9-18^{\circ} \mathrm{E}$, and that the explained variance of the SST anomalies averaged in the $150 \mathrm{~km}$ coastal band between $16^{\circ} \mathrm{S}$ and $34^{\circ} \mathrm{S}$ is about $80 \%$. This mode clearly represents an offshore signature of the coastal upwelling variability. The lagged-composites for the cold and warm subseasonal SST events evidence that corresponding SST anomalies propagate from the coast to offshore and are consistent with the wind stress fluctuations. Thus, although OI TMI SST data are not available over about $100 \mathrm{~km}$ off the coast, they can provide useful material for investigating the coastal upwelling variability at subseasonal scales.

[66] Two dominant regimes of SST variability are evidenced: a submonthly regime (2-30 days) with a dominant 11 days oscillation and a lower frequency intraseasonal regime (30-90 days) with a dominant 61 days oscillation. Both regimes are shown to be modulated, to a large extent, by wind stress through Ekman dynamics. A marked seasonal (semiannual) cycle of the relationship between wind stress and SST observed for the intraseasonal (submonthly) regime is interpreted in terms of the impact of seasonal change of the upper ocean stratification on the vertical advection process.

[67] An interesting and challenging issue arising from our analysis is related to the connection between SST subseasonal variability and the large-scale atmospheric conditions. In particular, the large-scale patterns associated with the two regimes of wind-driven SST variability indicate an important role of the eastward propagating disturbances at the midlatitudes corresponding to a wave number 4 . The intraseasonal variability in the central Benguela upwelling system is also strongly modulated by the intraseasonal component of the AAO. It would be interesting based on 
our methodology to investigate if the modulation of the AAO by other climate modes (such as, MJO or ENSO) can have an expression in the coastal upwelling at the intraseasonal time scale. This will require building long-term regional SST and wind products based on high-resolution modeling, which is a work under progress.

[68] Overall, our study based on observations can provide a benchmark for validating high-resolution regional models and designing model experiments. The realistic simulation of the subseasonal variability in the central Benguela upwelling system would allow a detailed analysis of all terms contributing to the rate of SST changes at the subseasonal scale, as well as, of the relative roles of local and remote forcing to the subseasonal SST variability.

[69] Acknowledgments. The authors wish to acknowledge use of the Ferret program (http://ferret.pmel.noaa.gov) for analysis and graphics in this paper. Ferret is a product of NOAA's Pacific Marine Environmental Laboratory. TMI data are produced by Remote Sensing Systems and sponsored by the NASA Earth Science MEaSUREs DISCOVER Project. Wind stress data were obtained from the Centre de Recherche et d'Exploitation Satellitaire (CERSAT), at IFREMER, Plouzané (France). We thank the CNES (Centre National d'Etudes Spatiales, France) (OSTST project EBUS-SOUTH) and ESA (The European Space Agency) (project OceanFlux) for financial support. Katerina Goubanova was supported by postdoctoral fellowships from CNES and IRD (Institut de Recherche pour le Développement, France). We thank Isabelle Dadou and Bruno Michon for stimulating discussions. The three anonymous reviewers are also thanked for their constructive comments.

\section{References}

Alory, G., A. Vega, A. Ganachaud, and M. Despinoy (2006), Influence of upwelling, subsurface stratification, and heat fluxes on coastal sea surface temperature off southwestern New Caledonia, J. Geophys. Res., 111, C07023, doi:10.1029/2005JC003401.

Bedacht, E., S. K. Gulev, and A. Macke (2007), Intercomparison of global cloud cover fields over oceans from the VOS observations and NCEP/ NCAR reanalysis, Int. J. Climatol., 27(13), 1707-1719.

Bourassa, M. A., D. M. Legler, J. J. O’Brien, and S. R. Smith (2003), SeaWinds validation with research vessels, J. Geophys. Res., 108(C2), 3019 , doi: 10.1029/2001JC001028.

Carton, J. A., and B. S. Giese (2008), A reanalysis of ocean Climate using Simple Ocean Data Assimilation(SODA), Mon. Weather Rev., 136(8), 2999-3017.

Carvalho, L. M. V., C. Jones, and T. Ambrizzi (2005), Opposite phases of the Antarctic Oscillation and relationships with intraseasonal to interannual activity in the tropics during the austral summer, J. Clim., 18, 702718.

Chelton, D. B., and M. H. Freilich (2005), Scatterometer-based assessment of 10-m wind analyses from the operational ECMWF and NCEP numerical weather prediction models, Mon. Weather Rev., 133, 409-429.

Clarke, A. J., and C. Shi (1991), Critical frequencies at ocean boundaries, J. Geophys. Res., 96, 10,731-10,738.

Colberg, F., and C. J. C. Reason (2006), A model study of the Angola Benguela Frontal Zone: Sensitivity to atmospheric forcing, Geophys. Res Lett., 33, L19608, doi:10.1029/2006GL027463.

Dewitte, B., S. Illig, L. Parent, Y. duPenhoat, L. Gourdeau, and J. Verron (2003), Tropical Pacific baroclinic mode contribution and associated long waves for the 1994-1999 period from an assimilation experiment with altimetric data, J. Geophys. Res., 108(C4), 3121, doi:10.1029/ 2002JC001362.

Dewitte, B., S. Purca, S. Illig, L. Renault, and B. Giese (2008), Low frequency modulation of the intraseasonal equatorial Kelvin wave activity in the Pacific Ocean from SODA: 1958-2001, J. Clim., 21, 6060-6069, doi:10.1175/2008JCLI2277.1.

Dewitte, B., S. Illig, L. Renault, K. Goubanova, K. Takahashi, D. Gushchina, K. Mosquera, and S. Purca (2011), Modes of covariability between sea surface temperature and wind stress intraseasonal anomalies along the coast of Peru from satellite observations (2000-2008), J. Geophys. Res., 116, C04028, doi:10.1029/2010JC006495.
Doi, T., T. Tozuka, H. Sasaki, Y. Masumoto, and T. Yamagata (2007) Seasonal and interannual variations of oceanic conditions in the Angola Dome, J. Phys. Oceanogr., 37, 2698-2713, doi:10.1175/2007JPO3552.1.

Duchon, C. (1979) Lanczos filtering in one and two dimensions, J. Appl. Meteorol., 18, 1016-1022.

Ebuchi, N., H. C. Graber, and M. J. Caruso (2002), Evaluation of wind vectors observed by QuikSCAT/SeaWinds using ocean buoy data, J. Atmos. Oceanic Technol., 19, 2049-2062.

Estrade, P., P. Marchesiello, A. Colin de Verdiere, and C. Roy (2008) Cross-shelf structure of coastal upwelling: A two-dimensional expansion of Ekman's theory and a mechanism for innershelf upwelling shut down, J. Mar. Res., 66, 589-616.

Florenchie, P., J. R. E. Lutjeharms, C. J. C. Reason, S. Masson, and M. Rouault (2003), The source of Benguela Niños in the South Atlantic Ocean, Geophys. Res. Lett., 30(10), 1505, doi:10.1029/2003GL017172.

Florenchie, P., C. J. C. Reason, J. R. E. Lutjeharms, M. Rouault, C. Roy, and S. Masson (2004), Evolution of interannual warm and cold events in the Southeast Atlantic Ocean, J. Clim., 17(12), 2318-2334.

Fox-Kemper, B., and R. Ferrari (2008), Parameterization of mixed layereddies. Part II: Prognosis and impact, J. Phys. Oceanogr., 38, 1166-1179.

Gentemann, C., C. J. Donlon, A. Stuart-Menteth, and F. J. Wentz (2003), Diurnal signals in satellite sea surface temperature measurements, Geophys. Res. Lett., 30(3), 1140, doi:10.1029/2002GL016291.

Gentemann, C., F. J. Wentz, M. Brewer, K. Hiburn, and D. Smith (2010), Passive microwave remote sensing of the ocean: An overview, in Oceanography from Space, Revisited, edited by V. Barale, J. Gower, and L. Alberotanza, pp.13-33, Springer, Heidelberg, Germany.

Han, W., P. J. Webster, J. Lin, W. T. Liu, R. Fu, D. Yuan, and A. Hu (2008), Dynamics of intraseasonal sea level and thermocline variability in the equatorial Atlantic during 2002-2003, J. Phys. Oceanogr., 38, 945-967.

Hayashi, Y. (1982), Space-time spectral analysis and its applications to atmospheric waves, J. Meteorol. Soc. Jpn., 60, 156-171.

Hermes, J. C., and C. J. C. Reason (2009), Variability in sea-surface temperature and winds in the tropical south-east Atlantic Ocean and regional rainfall relationships, Int. J. Climatol., 29(1), 11-21.

Hormazábal, S., G. Shaffer, J. Letelier, and O. Ulloa (2001), Local and remote forcing of sea surface temperature in the coastal upwelling system off Chile, J. Geophys. Res., 106(C8), 16,657-16,671.

Hutchings, L. et al. (2009), The Benguela Current: An ecosystem of four components, Progress Oceanogr., 83(1-4), 15-32.

Illig, S., B. Dewitte, N. Ayoub, Y. du Penhoat, G. Reverdin, P. De Mey, F. Bonjean, and G. S. E. Lagerloef (2004), Interannual long equatorial waves in the tropical Atlantic from a high resolution OGCM experiment in 1981-2000, J. Geophys. Res., 109, C02022, doi:10.1029/ $2003 \mathrm{jc} 001771$.

Jury, M. R. (2013), Physical oceanographic influences on Central Benguela fish catch, Earth Interact., 16, 1-15.

Kalnay, E. et al. (1996), The NCEP/NCAR 40year reanalysis project, Bull. Am. Meteorol. Soc., 77, 437-471.

Kidson, J. W. (1991), Intraseasonal variations in the southern hemisphere circulation, J. Clim., 4, 939-953.

Kiladis, G. N., and K. C. Mo (1998), Interannual and intraseasonal variability in the Southern Hemisphere, in Meteorology of the Southern Hemisphere, Meteorol. Monogr., chap. 8, vol. 27, edited by D. J. Karoly and D. G. Vincent, pp. 307-336, Am. Meteorol. Soc., Orlando, Fla.

Klein, S. A., and D. Hartmann (1993), The seasonal cycle of low stratiform clouds, J. Clim., 6, 1587-1606.

Kummerow, C. et al. (2000), The status of the Tropical Rainfall Measuring Mission (TRMM) after two years in orbit, J. Appl. Meteorol., 39, 1965-1982.

L'Heureux, M. L., and W. J. Thompson (2006), Observed relationships between the El Niño-Southern Oscillation and the extratropical zonalmean circulation, J. Clim., 19, 276-287.

Lin, J. W. B., J. D. Neelin, and N. Zeng (2000), Maintenance of tropical intraseasonal variability: Impact of evaporation-Wind feedback and midlatitude storms, J. Atmos. Sci., 57, 2793-2823.

Lübbecke, J. F., C. W. Böning, N. S. Keenlyside, and S.-P. Xie (2010), On the connection between Benguela and equatorial Atlantic Niños and the role of the South Atlantic Anticyclone, J. Geophys. Res., 115, C09015, doi: 10.1029/2009JC005964.

Lutjeharms, J. R. E., and J. M. Meeuwis (1987), The extent and variability of SE Atlantic upwelling, S. Afr. J. Mar. Sci., 5, 51-62.

Madden, R. A., and P. R. Julian (1994), Observations of the 40-50-day tropical oscillation-A review, Mon. Weather Rev., 122, 814-837. 
Marchesiello, P., and P. Estrade (2010), Upwelling limitation by geostrophic onshore flow, J. Mar. Res., 68, 37-62.

Mohrholz, V., M. Schmidt, and J. R. E. Lutjeharms (2001), The hydrography and dynamics of the Angola-Benguela frontal zone and environment in April 1999, S. Afr. J. Sci., 97, 199-208.

Negri, A. J., L. B. Thomas, and X. Liming (2002), Sampling of the diurnal cycle of precipitation using TRMM, J. Atmos. Oceanic Technol., 19, 1333-1344.

Nicholson, S. E. (2009), A low-level jet along the Benguela coast, an integral part of the Benguela current ecosystem, Clim. Change, 99(3-4), 613-624.

Pedlosky, J. (1987), Geophysical Fluid Dynamics, 2nd ed., 710 pp., Springer, New York.

Peterson, R., and L. Stramma (1991), Upper-level circulation in the South Atlantic Ocean, Prog. Oceanogr., 26(1), 1-73.

Pohl, B., and N. Fauchereau (2012), The southern annular mode seen through weather regimes, J. Clim., 25(9), 3336-3354.

Pohl, B., N. Fauchereau, C. J. C. Reason et, and M. Rouaut (2010), Relationships between the Antarctic oscillation, the Madden-Julian oscillation, and ENSO, and consequences for rainfall analysis, J. Clim., 23(2), 238-254.

Polo, I., A. Lazar, B. Rodriguez-Fonseca, and S. Arnault (2008), Oceanic Kelvin waves and tropical Atlantic intraseasonal variability: 1. Kelvin wave characterization, J. Geophys. Res., 113, C07009, doi:10.1029/ 2007JC004495.

Rahn, D. A. (2012), Influence of large scale oscillations on upwellingfavourable coastal wind off central Chile, J. Geophys. Res., 117, D19114, doi:10.1029/2012JD018016.

Renault, L., B. Dewitte, M. Falvey, R. Garreaud, V. Echevin, and F. Bonjean (2009), Impact of atmospheric coastal jets on SST off central Chile from satellite observations (2000-2007), J. Geophys. Res., 114, C08006, doi:10.1029/2008JC005083.

Reynolds, R. W., C. L. Gentemann, and G. K. Corlett (2010), Evaluation of AATSR and TMI satellite SST data, J. Clim., 23, 152-165, doi:http:// dx.doi.org/10.1175/2009JCLI3252.1.

Richter, I., S. K. Behera, Y. Masumoto, B. Taguchi, N. Komori, and T. Yamagata (2010), On the triggering of Benguela Niños: Remote equatorial versus local influences, Geophys. Res. Lett., 37, L20604, doi:10.1029/2010GL044461.

Ridgway, K. R., J. R. Dunn, J. L. Wilkin (2002), Ocean interpolation by 4-dimensional weighted least squares-Application to the waters around Australasia, J. Atmos. Oceanic Technol., 19, 1357-1375.

Risien, C. M., C. J. C. Reason, F. A. Shillington, and D. B. Chelton (2004), Variability in satellite winds over the Benguela upwelling system during
1999-2000, J. Geophys. Res., 109, C03010, doi:10.1029/ 2003JC001880.

Rogers, J. C., and H. Van Loon (1982), Spatial variability of sea level pressure and height anomalies over the Southern Hemisphere, Mon. Weather Rev., 110, 1375-1392.

Rouault, M. (2012), Bi-annual intrusion of tropical water in the northern Benguela upwelling, Geophys. Res. Lett., 39, L12606, doi:10.1029/ 2012GL052099.

Rouault, M., and J. R. E. Lutjeharms (2003), Microwave satellite remote sensing of SST around Southern Africa, S. Afr. J. Sci., 99, 489-494.

Rouault, M., S. Illig, C. Bartholomae, C. J. C. Reason, and A. Bentamy (2007), Propagation and origin of warm anomalies in the Angola Benguela upwelling system in 2001, J. Mar. Syst., 68, 473-488.

Rouault, M., B. Pohl, and P. Penven (2010), Coastal Oceanic climate change and variability from 1982 to 2009 around South Africa, Afr. J. Mar. Sci., 32(2), 237-246.

Rutllant, J., B. Rosenbluth, and S. Hormazabal (2004), Intraseasonal variability in the local wind forcing of coastal upwelling off central Chile (30 S), Cont. Shelf Res., 24, 789-804, doi:10.1016/j.csr.2004.02.004.

Schouten, M. W., R. P. Matanoand, and T. P. Strub (2005), A description of the seasonal cycle of the equatorial Atlantic from altimeter data, Deep Sea Res., 52, 477-493.

Shannon, L. V., and G. Nelson (1996), The Benguela: Large scale features and processes and system variability, in The South Atlantic: Present and Past Circulation, edited by G. Wefer et al., pp. 163-210, Springer, New York

Shannon, L. V., A. J. Boyd, G. B. Brundrit, and J. Tauton-Clarke (1986), On the existence of an El Niño-type Phenomenon in the Benguela System, J. Mar. Res., 44, 495-520.

Torrence, C., and G. P. Compo (1998), A practical guide to wavelet analysis, Bull. Am. Meteorol. Soc., 79, 61-78.

Veitch, J., P. Florenchie, and F. Shillington (2006), Seasonal and interannual fluctuations of the Angola-Benguela frontal zone (ABFZ) using 4.5 $\mathrm{km}$ resolution satellite imagery from 1982 to 1999 , Int. J. Remote Sens., 27, 987-998, doi:10.1080/01431160500127914.

Veitch, J. A., P. Penven, and F. A. Shillington (2010), Modelling equilibrium dynamics of the Benguela Current system, J. Phys. Oceanogr., 40, 1942-1964.

vonStorch, H., and F.W. Zwiers (1999), Statistical Analysis in Climate Research, 494 pp., Cambridge Univ. Press, Cambrigde, UK.

Xu, H., S-P. Xie, and Y. Wang (2005), Subseasonal variability of the southeast Pacific stratus cloud deck, J. Clim., 18, 131-142. 